\title{
Expression of endocannabinoid system components in human airway epithelial cells: impact of sex and chronic respiratory disease status
}

\author{
Matthew F. Fantauzzi ${ }^{1,2}$, Jennifer A. Aguiar³, Benjamin J.-M. Tremblay ${ }^{3}$, \\ Michael J. Mansfield (10 ${ }^{4}$, Toyoshi Yanagihara (1) ${ }^{1}$, Abiram Chandiramohan ${ }^{1}$, \\ Spencer Revill ${ }^{1}$, Min Hyung Ryu ${ }^{5}$, Chris Carlsten $\mathbb{1}^{5}$, Kjetil Ask (1) ${ }^{1,2}$, \\ Martin Stämpfli, ${ }^{1,2}$, Andrew C. Doxey ${ }^{1,3}$ and Jeremy A. Hirota ${ }^{1,2,3,5}$
}

Affiliations: ${ }^{1}$ Firestone Institute for Respiratory Health - Division of Respirology, Dept of Medicine, McMaster University, Hamilton, ON, Canada. ${ }^{2}$ McMaster Immunology Research Centre, McMaster University, Hamilton, ON, Canada. ${ }^{3}$ Dept of Biology, University of Waterloo, Waterloo, ON, Canada. ${ }^{4}$ Genomics and Regulatory Systems Unit, Okinawa Institute of Science and Technology Graduate University, Onna, Japan. ${ }^{5}$ Division of Respiratory Medicine, Dept of Medicine, University of British Columbia, Vancouver, BC, Canada.

Correspondence: Jeremy Hirota, Firestone Institute for Respiratory Health - Division of Respirology, Dept of Medicine, McMaster University, Hamilton, ON, L8N 4A6, Canada. E-mail: hirotajaAmcmaster.ca

ABSTRACT Cannabis smoking is the dominant route of delivery, with the airway epithelium functioning as the site of first contact. The endocannabinoid system is responsible for mediating the physiological effects of inhaled phytocannabinoids. The expression of the endocannabinoid system in the airway epithelium and contribution to normal physiological responses remains to be defined.

To begin to address this knowledge gap, a curated dataset of 1090 unique human bronchial brushing gene expression profiles was created. The dataset included 616 healthy subjects, 136 subjects with asthma, and 338 subjects with COPD. A 32-gene endocannabinoid signature was analysed across all samples with sex and disease-specific analyses performed. Immunohistochemistry and immunoblots were performed to probe in situ and in vitro protein expression.

$\mathrm{CB}_{1}, \mathrm{CB}_{2}$, and TRPV1 protein signal is detectable in human airway epithelial cells in situ and in vitro, justifying examining the downstream endocannabinoid pathway. Sex status was associated with differential expression of 7 of 32 genes. In contrast, disease status was associated with differential expression of 21 of 32 genes in people with asthma and 26 of 32 genes in people with COPD. We confirm at the protein level that TRPV1, the most differentially expressed candidate in our analyses, was upregulated in airway epithelial cells from people with asthma relative to healthy subjects.

Our data demonstrate that the endocannabinoid system is expressed in human airway epithelial cells with expression impacted by disease status and minimally by sex. The data suggest that cannabis consumers may have differential physiological responses in the respiratory mucosa.

@ERSpublications

The endocannabinoid system is differentially expressed in human airway epithelial cells from healthy subjects compared to those with asthma or COPD, which may be relevant for population-specific responses to inhaled cannabis smoke https://bit.ly/3cEWc2h

Cite this article as: Fantauzzi MF, Aguiar JA, Tremblay BJ-M, et al. Expression of endocannabinoid system components in human airway epithelial cells: impact of sex and chronic respiratory disease status. ERJ Open Res 2020; 6: 00128-2020 [https://doi.org/10.1183/23120541.00128-2020].

This article has been revised according to the author correction published in ERJ Open Res 2021; 7: 50128-2020 [https:// doi.org/10.1183/23120541.50128-2020].

This article has supplementary material available from openres.ersjournals.com.

Received: 11 March 2020 | Accepted after revision: 18 Sep 2020 | First published: 15 Dec 2020

Copyright $\odot$ ERS 2020. This article is open access and distributed under the terms of the Creative Commons Attribution Non-Commercial Licence 4.0. 


\section{Introduction}

Cannabis is the most commonly consumed illicit drug worldwide, with prevalence expected to increase due to trends in legalisation and innovations in medicinal applications [1]. Canada legalised cannabis in 2017 and concomitantly initiated the annual Canadian Cannabis Survey to monitor the perception and use patterns, demonstrating that $20 \%$ of the general population consumes cannabis [2-4]. Over $90 \%$ of cannabis consumers identified combusted smoke inhalation as a route of delivery, highlighting the lung as the dominant target for cannabis exposures. Within the cannabis consumer population, there is a skewed distribution of use patterns with males more frequently consuming in the past 12 months relative to females (26\% versus $18 \%$ ) with a subset $(12 \%)$ of the population using cannabis for medicinal purposes. The prospective design of the Canadian Cannabis Surveys has demonstrated that cannabis use over time is widely accepted at a population level for recreational and medicinal purposes with no signal for decline in use post-legalisation [2-4]. Additionally, the data demonstrate a strong preference for inhalation routes of delivery and a skewing between male and female use. Therefore, a generalised understanding of how a cannabis consumer responds to smoke exposure is likely to be insufficient and should include both females and males in analyses and consider both healthy individuals and those that may have underlying medical needs.

The Canadian Cannabis Surveys report of inhalation as a dominant route of delivery confirms the importance of focusing on how the lungs respond to cannabis exposures. Early clinical exposure studies demonstrated that acute cannabis smoke exposure in healthy subjects is able to provide a sustained increase in lung function, which contrasted tobacco smoke inhalation $[5,6]$. In people with asthma, cannabis smoking is able to produce a rapid reversal of exercise-induced bronchoconstriction and minimises bronchoconstriction induced by methacholine inhalation $[7,8]$. Despite these objective benefits in a controlled laboratory setting, critical consideration needs to be given to the observed negative impacts on lung function in the context of increased frequency and intensity of cannabis smoking. Contrasting with acute cannabis exposure, cannabis smoking over a 2-month period was associated with a decrease in airway compliance that was correlated with quantity of cannabis consumed [9]. Further consolidating the negative impacts of chronic cannabis use on lung health, population-level analyses reveal that greater intensity of cannabis smoking is correlated with reduced lung function and increased risk of developing COPD [10, 11]. Furthermore, in multiple independent cohorts, cannabis smoking has been associated with a proinflammatory phenotype in the lung, associated with bronchitis and impaired immune cell function [12-16]. The mechanism(s) responsible for the clinical observations resulting from cannabis inhalation, whether beneficial acute or detrimental chronic exposures, remain elusive, but are likely to be influenced by the endocannabinoid system [17-19].

The endocannabinoid system is responsible for mediating the pharmacological effects of the endogenous cannabinoids anandamide and 2-arachidonylglycerol (2-AG) and some phytocannabinoids present in cannabis [20-22]. The first identified cannabinoid receptors were $\mathrm{CB}_{1}$ and $\mathrm{CB}_{2}$, both G-protein-coupled receptors that modulate downstream cyclic AMP signalling by inhibiting adenylyl cyclase activity [23, 24]. The mechanism of acute phytocannabinoid-induced bronchodilation is suggested to be mediated via $\mathrm{CB}_{1}$ receptors regulating neural control of airway tone [17, 18], which may have benefits for management of bronchoconstriction in asthma or COPD. In addition to $\mathrm{CB}_{1}$ and $\mathrm{CB}_{2}$, the transient receptor potential vanilloid-1 (TRPV1) and GPR55 have been identified as receptors for cannabinoids [25, 26]. Although the endocannabinoid signalling pathway is present throughout multiple tissues and organ systems, the lungs are of particular interest as they are the organ system targeted by cannabis inhalation. Airway epithelial cells play a critical role in lung health by acting as the first line of defence against pathogens and inhaled insults [27-29]. Airway epithelial cells carry out a number of functions such as providing a physical barrier against microbial infiltration, maintaining the inflammatory microenvironment, and releasing immune mediators to recruit leukocytes to the site of insult. It has been demonstrated that the inhalation of air pollution, tobacco smoke, and cannabis smoke can compromise airway epithelial function [30-32]. Notably, recent findings show that cannabis smoke exposure can lead to impaired airway epithelium barrier integrity, attenuated antiviral capacity, and exacerbated inflammatory response to immune challenges [31, 32]. However, the contribution of the endocannabinoid system to these observations has not been defined. The primary cannabinoid receptors, $\mathrm{CB}_{1}$ and $\mathrm{CB}_{2}$, have been shown to be expressed in the respiratory mucosa $[33,34]$ and human airway epithelial cells are responsive to tetrahydrocannabinol and anandamide in vitro $[35,36]$. Additional components of the endocannabinoid system including MAPK, PI3K, and protein kinase-A signalling pathways downstream of receptors and enzymes responsible for cannabinoid metabolism have not been explored in an integrated fashion in human airway epithelial cells. An examination of the entire endocannabinoid system in human airway epithelial cells is required to better understand which components are dominant and likely to be functionally relevant in response to inhaled cannabis smoke. Furthermore, it remains possible that sex and disease status impact the endocannabinoid system expression, which may have functional consequences in distinct populations of cannabis consumers. 
To begin our interrogation of the endocannabinoid system in human airway epithelial cells, we first generated a 32-gene endocannabinoid signature encompassing ligand recognition, signalling, and metabolism. We set out to examine if the expression of this 32-gene endocannabinoid signature was present in human airway epithelial cells and whether this was impacted by sex or disease status. The importance on examining sex and disease status on the endocannabinoid system is due to the possibility that specific populations may experience differential effects of cannabis, either positive or negative. To complete this study, we used a bioinformatic approach to analyse gene expression in 1090 unique human subject samples of airway epithelial cells isolated via bronchial brushing that included samples from healthy males and females and individuals with asthma or COPD. We complement our bioinformatic approach with validation and confirmation of $\mathrm{CB}_{1}, \mathrm{CB}_{2}$, and TRPV1 in human airway epithelial cells at the protein and gene level in situ and in vitro. Lastly, we validate a bioinformatic observation that TRPV1 gene expression is elevated in airway epithelial cells isolated from people with asthma by performing confirmatory immunoblot analysis on primary human airway epithelial cells. Collectively, our results demonstrate that an intact endocannabinoid system is expressed in human airway epithelial cells and that disease status impacts expression to a greater extent than sex, which may have functional consequences that lead to differential responses in distinct populations of cannabis consumers.

\section{Methods}

Human ethics

All studies using primary human lung material and blood were approved by the Hamilton Integrated Research Ethics Board or the University of British Columbia Human Research Ethics Board. No information on cannabis smoking history was available for any of the analyses described in detail below (in situ protein expression, in vitro immunoblots, in situ hybridisation, and microarray gene expression).

\section{Primary human airway epithelial cells}

Primary human airway epithelial cells isolated via bronchial brushings from consented healthy or asthmatic subjects were grown in PneumaCult ExPlus (Stemcell Technologies, Vancouver Canada) under submerged monolayer culture conditions and used in between passage 1 and 4 . Where relevant, asthma diagnosis was confirmed with methacholine challenge and $\mathrm{PC}_{20}$ (provocative concentration causing a $20 \%$ fall in forced expiratory volume in $1 \mathrm{~s}$ ) analysis as per ATS guidelines. No information on underlying medication use was collected.

\section{Human whole-lung tissue}

Noninvolved tissues from lung cancer patients were used. Lungs were homogenised using a mechanical homogeniser (Omni International, Waterbuy, CT, USA), lysed in $1 \times$ lysis buffer supplemented with complete protease inhibitors (Roche), and the supernatant was collected for immunoblots. No information on underlying medication use was collected.

\section{Human peripheral blood mononuclear cells}

Human peripheral blood mononuclear cells (PBMCs) were isolated from the peripheral blood of healthy volunteers using Ficoll (Sigma-Aldrich) density centrifugation in Greiner LeucoSep-tubes (Sigma) according to the manufacturer's recommendations.

\section{Immunohistochemistry and in situ hybridisation}

Formalin-fixed paraffin-embedded human lung tissue from noninvolved regions of lung taken during resection were used for localisation of $\mathrm{CB}_{1}, \mathrm{CB}_{2}$, and TRPV1/VR1. Three-micron-thick sections were cut and stained for $\mathrm{CB}_{1}$ (Abcam, Ab23703, lot GR3239384-12 at 1:1000 dilution), $\mathrm{CB}_{2}$ (Abcam, Ab3561, lot GR3259180-6 at 1:50 dilution), and TRPV1/VR1 (Abcam, Ab3487, lot GR3296259-1 at $5 \mu \mathrm{g} \cdot \mathrm{mL}^{-1}$ ). All staining was performed on a Leica Bond RX system with Leica Bond reagents and heat-induced antigen retrieval in citrate buffer at $\mathrm{pH}$ 6. To confirm $\mathrm{CB} 1$ and $\mathrm{CB} 2$ protein expression, in situ hybridisation using RNAscope ${ }^{\oplus}$ technology was used to detect CNR1 (ACD, 591528) and CNR2 (ACD, 596028) transcripts on a Leica Bond RX system. Digital slide scanning was performed using an Olympus VS120-L100 Virtual Slide System at $\times 40$ magnification with VS-ASW-L100V2.9 software and a VC50 colour camera.

\section{Analysis of promoter activity from the FANTOM5 dataset}

The FANTOM5 promoterome dataset for the hg38 assembly was used to examine promoter activity of CNR1 and CNR2. Using the ZENBU genome browser, the nearest cap analysis of gene expression (CAGE) peak upstream and on the same strand as each of the aforementioned genes was extracted and analysed. The dataset consists of CAGE promoter activity data for 1886 primary cells, cell lines, and tissues from humans, and is quantified as normalised transcripts per million (TPM). A subset of FANTOM5 CAGE data (28 samples) is presented considering only samples related to lung tissues. Normalised TPM values 
for each CAGE peak, an approximation for promoter activity, were $\log _{10}$ transformed and separated according to tissue and cell type, and the heat map colour is proportional to these transformed normalised TPM values.

\section{Immunoblots}

Immunoblots confirming antibody staining and protein expression in human airway epithelial cells were performed using Bio-Rad stain-free $4-20 \%$ pre-cast gradient gels and imaged on a Bio-Rad ChemiDoc XRS+ Imaging system. For each immunoblot, $40 \mu \mathrm{g}$ of protein was added per lane. $\mathrm{CB}_{1}$ (Abcam, $\mathrm{Ab} 23703$ at 1:500 dilution), $\mathrm{CB}_{2}$ (Abcam, Ab3561 at 1:100 dilution), and TRPV1 (Abcam, Ab3487 at 1:500 dilution) were diluted in $5 \%$ skimmed milk/TBS with $0.1 \%$ Tween-20. Primary antibody detection was performed using an anti-rabbit-horseradish peroxidase-conjugated secondary (Cell Signalling Technology, 7074) at 1:1000 dilution for $50 \mathrm{~min}$ at room temperature. Visualisation was performed using Clarity ${ }^{\mathrm{TM}}$ Western ECL Substrate (Bio-Rad) $\left(\mathrm{CB}_{1}\right.$ and TRPV1) and SuperSignal ${ }^{\mathrm{TM}}$ West Femto Maximum Sensitivity Substrate (Thermo Fisher Scientific) $\left(\mathrm{CB}_{2}\right)$. Total protein loading images were collected as a confirmation of equal protein loading between sample types [37].

\section{Gene expression dataset curation, normalisation, and statistical analyses}

Candidate genes to be analysed were selected based on known relevance in the endocannabinoid signalling pathway. Additional genes and proteins implicated to be involved in cannabis-associated disorders and novel cannabinoid-based therapeutic approaches were included and described in annotated table format (table 1) [23-26, 38-60].

Public microarray experiments using Affymetrix chips (HG-U133 Plus 2, HuEx-1.0-st-v1 and HuGene-1.0-st-v1) on airway epithelial cell samples from healthy individuals or those with asthma or COPD were selected from the National Center for Biotechnology Information Gene Expression Omnibus database. Healthy samples were further filtered by removing former or current smokers. This resulted in a total of 1090 individual samples from 27 experiments (table 2) that included samples from 616 healthy subjects, 136 subjects with asthma, and 338 subjects with COPD [61-88]. Within each sample population, sex was reported for a subset of samples (healthy: 103 females/227 males; asthma: 34 females/28 males; COPD: 48 females/93 males). Within all datasets analysed, only 19 samples (from GSE4302) had information on medication use. For this reason, no stratification on medication use was possible for the bioinformatic analyses.

For all dataset samples, raw intensity values and annotation data were downloaded with the $\mathrm{R}$ statistical language (version 3.6.1; R Core Team, 2019) using the GEOquery R package (version 2.52.0) [89]. Probe definition files were downloaded from the Brainarray database (version 24) [90]. To obtain processed microarray gene expression values unaffected by probe CG compositional biases, the single channel array normalisation (SCAN) method was used via the SCAN.UPC R package (version 2.26.0) [91] using annotation data from the Bioconductor project (version 3.9) [92]. All $\log _{2}$-transformed gene expression data were unified into a single dataset, and only genes detected in all three platforms (16543) were kept for subsequent analyses. Correction of experiment-specific batch effects was performed using the ComBat method [93] implemented in the sva R package (version 3.32.1) [94], with disease status and sex supplied as covariates. Following batch correction, all data underwent Z-score transformation to set the mean of all samples to zero and replace expression values with a measure of variance from the mean [95]. Principal-component analysis (PCA) was performed using the probabilistic PCA method in the pcaMethods R package (version 1.76.0) [96]. Gene expression levels were tested for significant differences via a t-test with a Benjamini-Hochberg multiple testing correction using the stats $\mathrm{R}$ package (version 3.6.1; $\mathrm{R}$ Core Team, 2019). Gene expression box plots, heat maps, and PCA plots were generated with the ggplot2 R package (version 3.2.1).

\section{Results}

Human airway epithelial cells express $C B_{1}, C B_{2}$, and TRPV1, in situ and in vitro

A curated list of genes involved in cannabinoid signalling was generated (herein called the 32-gene endocannabinoid signature) to provide a focused overview of this pathway in human airway epithelial cells (figure 1 and table 1).

To begin our characterisation of the endocannabinoid system in human airway epithelial cells, we performed in situ localisation of $\mathrm{CB}_{1}, \mathrm{CB}_{2}$, and TRPV1 protein in human lung tissue (figure 2). We demonstrate that all three receptors are present at protein level in human airway epithelial cells in situ relative to negative control (figure $2 \mathrm{a}, \mathrm{c}$, e and $\mathrm{g}$ ). To validate the staining patterns observed and antibody specificity, we performed immunoblots with primary human airway epithelial cells, whole-lung tissue, and PBMCs. A single band for $\mathrm{CB}_{1}$ was observed at approximately $45 \mathrm{kDa}$ in human airway epithelial cells, but 
TABLE 1 Relevant endocannabinoid signalling pathway candidates

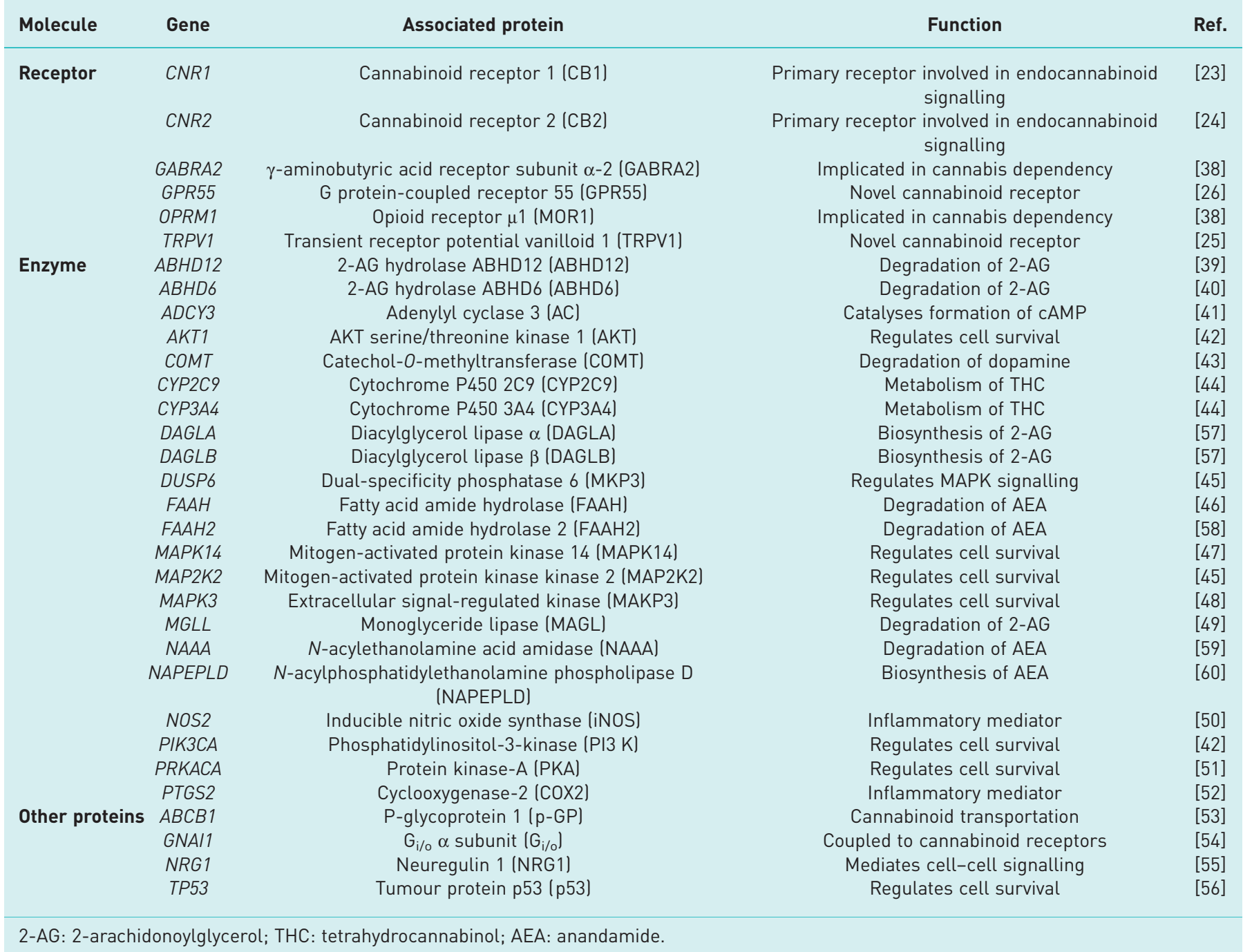

not whole human lung, or PBMCs (figure $2 \mathrm{~b}$ ). A dominant band for $\mathrm{CB}_{2}$ was observed at approximately $40 \mathrm{kDa}$ and accompanied by a reported $52-55 \mathrm{kDa}$ doublet [97] in human airway epithelial cells, with a similar pattern observed for PBMCs (figure $2 \mathrm{~d}$ ). In contrast, in whole human lung the dominant band was observed at $55 \mathrm{kDa}$ with only a faint $40 \mathrm{kDa}$ band. The band patterns observed for $\mathrm{CB}_{2}$ are consistent with glycosylation of the $\mathrm{N}$ terminus and processing of the full-length peptide [97]. A dominant band for TRPV1 was observed at approximately $100 \mathrm{kDa}$ in human airway epithelial cells and accompanied by two lower molecular weight bands at approximately $70 \mathrm{kDa}$ and $37 \mathrm{kDa}$ (figure $2 \mathrm{f}$ ). No TRPV1 bands were observed in whole human lung, while a dominant single band at $100 \mathrm{kDa}$ was observed in PBMCs. Total protein loading staining from a representative blot demonstrates equal loading within replicates of the same sample type and distinct protein compositions between sample types (figure $2 \mathrm{~h}$ ).

To extend our in situ $\mathrm{CB}_{1}$ and $\mathrm{CB}_{2}$ protein staining and to interrogate the potential of nonspecific staining generated with the CB2 antibody, we next performed in situ hybridisation for CNR1 and CNR2 gene transcripts using RNAscope ${ }^{\star}$ technology (figure 3). In situ hybridisation demonstrates transcripts for both CNR1 (figure 3a) and CNR2 (figure 3b) in the airway epithelium of all human lung samples examined $(\mathrm{n}=10)$. Serial sections from each lung sample reveal that CNR1 and CNR2 are likely to coexpress in airway epithelium.

To further corroborate our in situ $\mathrm{CB}_{1}$ and $\mathrm{CB}_{2}$ protein and gene transcript staining, promoter activity data for CNR1 and CNR2 were extracted and analysed from the FANTOM5 dataset, which includes 1886 


\begin{tabular}{|c|c|c|c|c|c|}
\hline GSE accession & Affymetrix chip & Asthma & COPD & Healthy & Ref. \\
\hline GSE4302 & HG-U133 Plus 2 & 74 & 0 & 13 & {$[61,62]$} \\
\hline GSE4498 & HG-U133 Plus 2 & 0 & 0 & 12 (2F/10M) & {$[63,64]$} \\
\hline GSE5058 & HG-U133 Plus 2 & 0 & $14(4 \mathrm{~F} / 10 \mathrm{M})$ & 0 & {$[64,65]$} \\
\hline GSE7832 & HG-U133 Plus 2 & 0 & 0 & $8(2 F / 6 M)$ & [64] \\
\hline GSE8545 & HG-U133 Plus 2 & 0 & 15 (3F/12M) & $5(1 F / 4 M)$ & [66] \\
\hline GSE10006 & HG-U133 Plus 2 & 0 & $20(4 \mathrm{~F} / 16 \mathrm{M})$ & $21(2 F / 19 M)$ & [67] \\
\hline GSE11784 & HG-U133 Plus 2 & 0 & $17(1 \mathrm{~F} / 3 \mathrm{M})$ & $40(18 \mathrm{~F} / 22 \mathrm{M})$ & [68] \\
\hline GSE11906 & HG-U133 Plus 2 & 0 & 0 & 30 (10F/20M) & [69] \\
\hline GSE13931 & HG-U133 Plus 2 & 0 & 0 & 19 (4F/15M) & [70] \\
\hline GSE13933 & HG-U133 Plus 2 & 0 & 0 & $11(6 \mathrm{~F} / 5 \mathrm{M})$ & [71] \\
\hline GSE14224 & HuEx-1.0-st-v2 & 0 & 0 & $11(7 F / 4 M)$ & [72] \\
\hline GSE17905 & HG-U133 Plus 2 & 0 & 0 & $1(1 \mathrm{M})$ & [73] \\
\hline GSE19667 & HG-U133 Plus 2 & 0 & 0 & $3(3 F)$ & {$[74]$} \\
\hline GSE20257 & HG-U133 Plus 2 & 0 & $1(1 F)$ & 0 & [75] \\
\hline GSE22047 & HG-U133 Plus 2 & 0 & 23 & 81 & [76] \\
\hline GSE34450 & HG-U133 Plus 2 & 0 & 0 & 11 & [77] \\
\hline GSE37147 & HuGene-1.0-st-v1 & 0 & $110(35 \mathrm{~F} / 52 \mathrm{M})$ & 8 & [100] \\
\hline GSE40364 & HG-U133 Plus 2 & 0 & 7 & 0 & [79] \\
\hline GSE43079 & HG-U133 Plus 2 & 0 & 0 & 16 & [80] \\
\hline GSE43939 & HG-U133 Plus 2 & 0 & 0 & 13 & [81] \\
\hline GSE52237 & HG-U133 Plus 2 & 0 & 0 & 2 & [82] \\
\hline GSE64614 & HG-U133 Plus 2 & 0 & 0 & 31 & [83] \\
\hline GSE67472 & HG-U133 Plus 2 & 62 (34F/28M) & 0 & 43 (20F/23M) & [84] \\
\hline GSE77658 & HG-U133 Plus 2 & 0 & 0 & 6 & [85] \\
\hline GSE84101 & HG-U133 Plus 2 & 0 & 0 & 7 & [86] \\
\hline GSE97010 & HuGene-1.0-st-v1 & 0 & 0 & $126(28 \mathrm{~F} / 98 \mathrm{M})$ & [87] \\
\hline GSE108134 & HG-U133 Plus 2 & 0 & 131 & 98 & [88] \\
\hline
\end{tabular}

primary cells, cell lines, and tissue sample types. We selected all samples that included "lung", "nasal", "trachea", "bronchial", "airway", or "alveolar" to identify lung-specific sample types (n=28). CDH1 promoter activity was analysed as a positive control. Consistent with our observed gene expression analysis in airway epithelial cells, normalised TPM values for each CAGE peak demonstrate that CNR1 and CNR2 promoter activity was present but modest across airway epithelial cells and lung tissue samples (supplementary figure 1). Both microarray gene expression analysis and promoter activity were consistent with results of candidate gene and protein expression in airway epithelial cells via in situ hybridisation and immunohistochemistry.

Collectively, our in situand in vitro data are supportive for expression of $\mathrm{CB}_{1}, \mathrm{CB}_{2}$, and TRPV1 protein and gene in human airway epithelial cells.

\section{Expression of endocannabinoid system genes in human airway epithelial cells from healthy male and female subjects}

Sex differences in $\mathrm{CB}_{1}$ and $\mathrm{CB}_{2}$ expression levels have been reported [98], which could impact downstream responses to cannabinoid exposures. Furthermore, sex and gender differences in cannabis consumption practices have been reported [2-4]. Collectively, these two factors could interact and contribute to differential responses to cannabinoids in distinct populations.

To examine sex differences in the endocannabinoid system, we analysed our 32-gene endocannabinoid signature in a curated dataset of airway epithelial cells from 616 unique healthy subjects, where the identifier of sex was available for 103 females and 227 males (table 2). The 32-gene endocannabinoid signature was first analysed in all 616 subjects to show overall trends for each gene (figure 4a). Subsequently, a PCA plot was performed for all samples with sex as an identifier (figure $4 \mathrm{~b}$ ). The PCA plot reveals clustering of samples from males within a larger space occupied by the female samples. Statistical analysis at the individual gene level revealed a difference in 7 of 32 genes (figure 4c). Five genes (ABHD6, MAPK14, NAAA, NRG1, and PIK3CA) were downregulated in males relative to females, while two genes (CYP2C9 and GPR55) were upregulated in males relative to females. The gene expression 


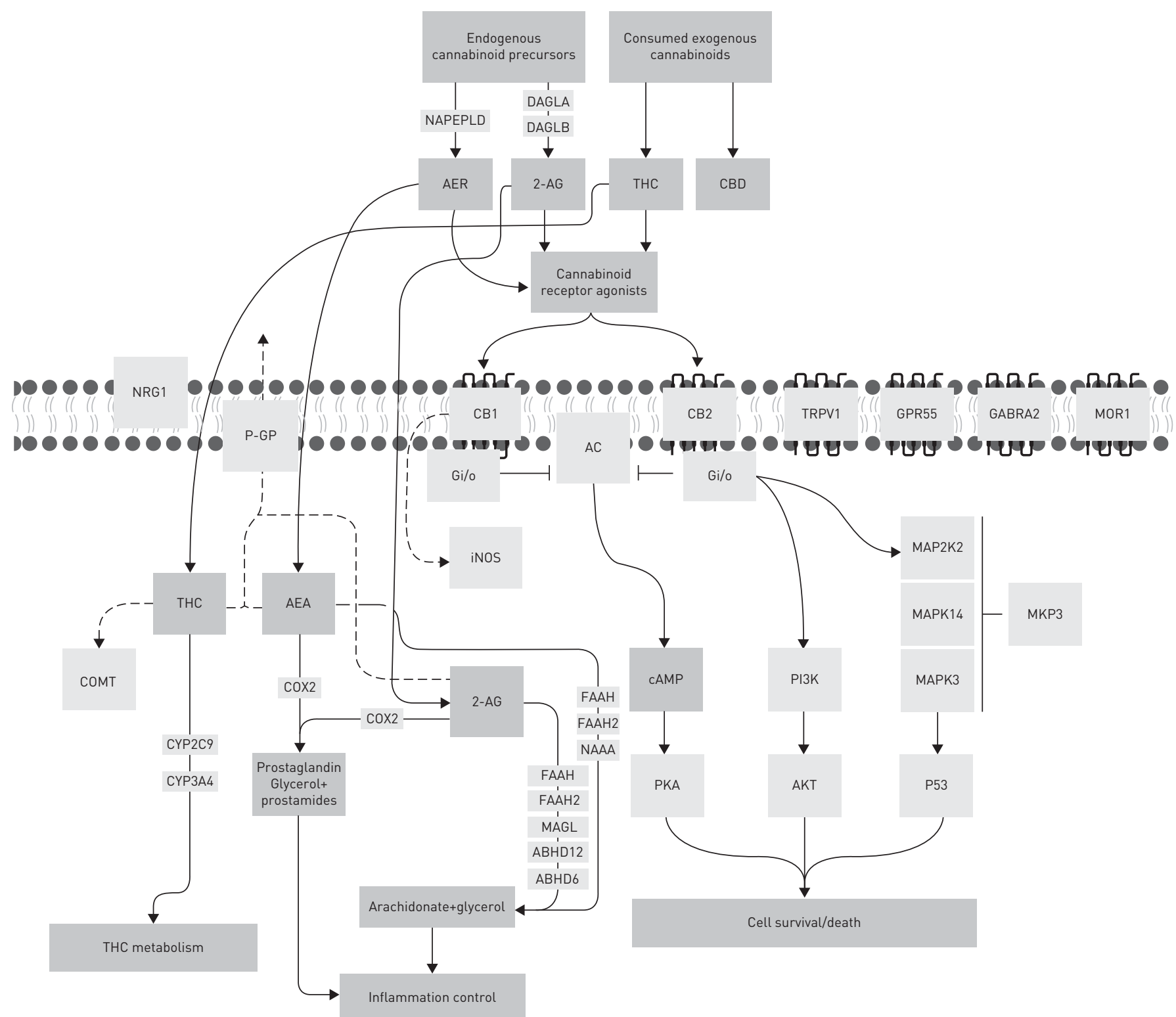

FIGURE 1 Visual representation a 32-gene endocannabinoid signature. Solid arrows indicate known relationship between candidates and ligands. Dotted arrows indicate proposed relationships. Blunted lines indicate inhibition. Candidate functions are annotated in table 1. THC: tetrahydrocannabinol.

patterns were overlaid on the endocannabinoid signalling pathway for qualitative visualisation of global changes in the 32-gene endocannabinoid signature in males relative to females (figure $4 \mathrm{~d}$ ).

Collectively, our data confirm that the endocannabinoid system is expressed at gene level in human airway epithelial cells, suggesting that signalling downstream of receptors is intact, with mild sex differences observed in endocannabinoid system gene expression.

The endocannabinoid system is dysregulated in human airway epithelial cells from individuals with asthma and COPD

In addition to sex, disease status may also impact the expression of the endocannabinoid system in airway epithelial cells, as specific phenotypes are observed in cells isolated from people with asthma and individuals with COPD [99-101]. We therefore tested the hypothesis that the 32-gene endocannabinoid signature was dysregulated in asthma and COPD.

To test this hypothesis, we curated all 1090 samples that included 616 healthy subjects, 136 subjects with asthma, and 338 subjects with COPD. A PCA plot reveals clustering of samples from healthy, asthmatic, 
a)

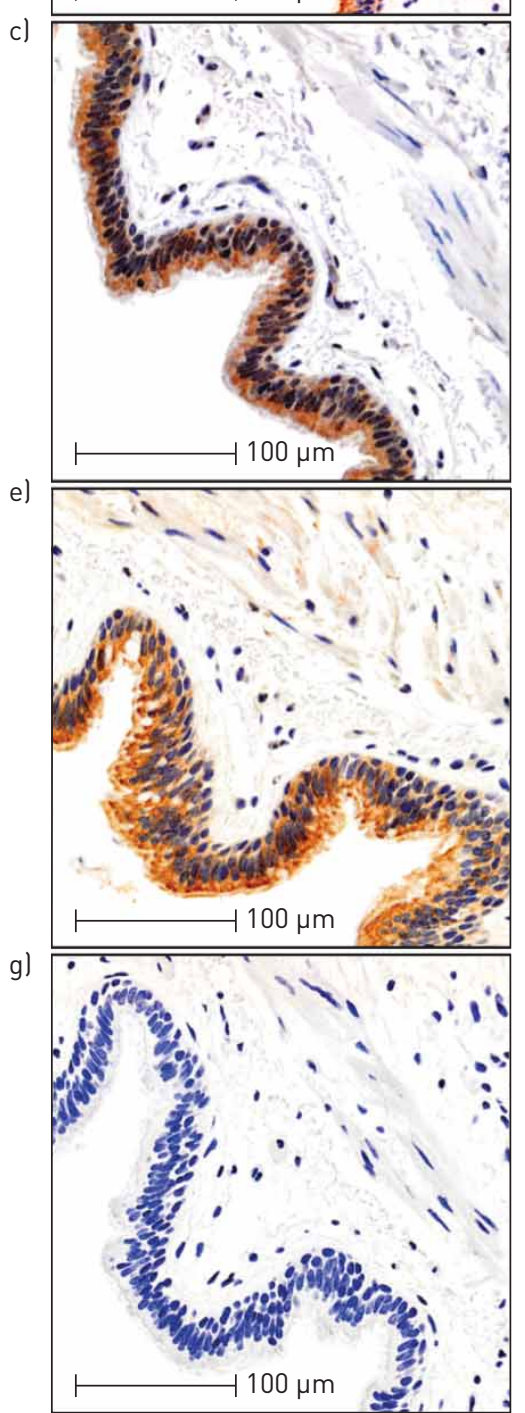

b)

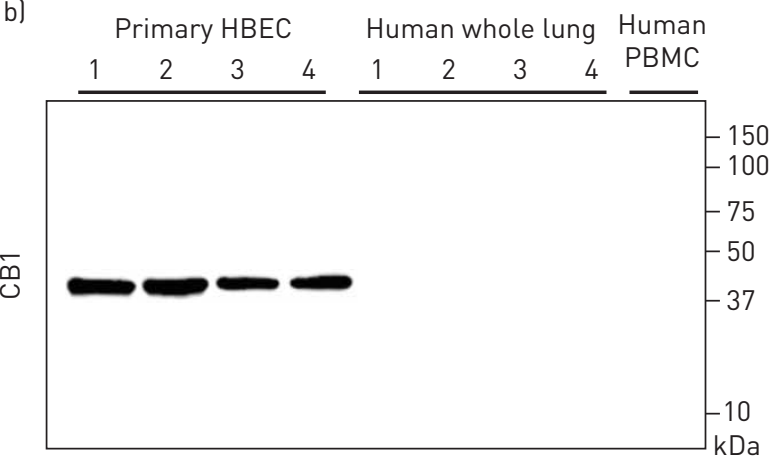

d)

d) Primary HBEC Human whole lung Human
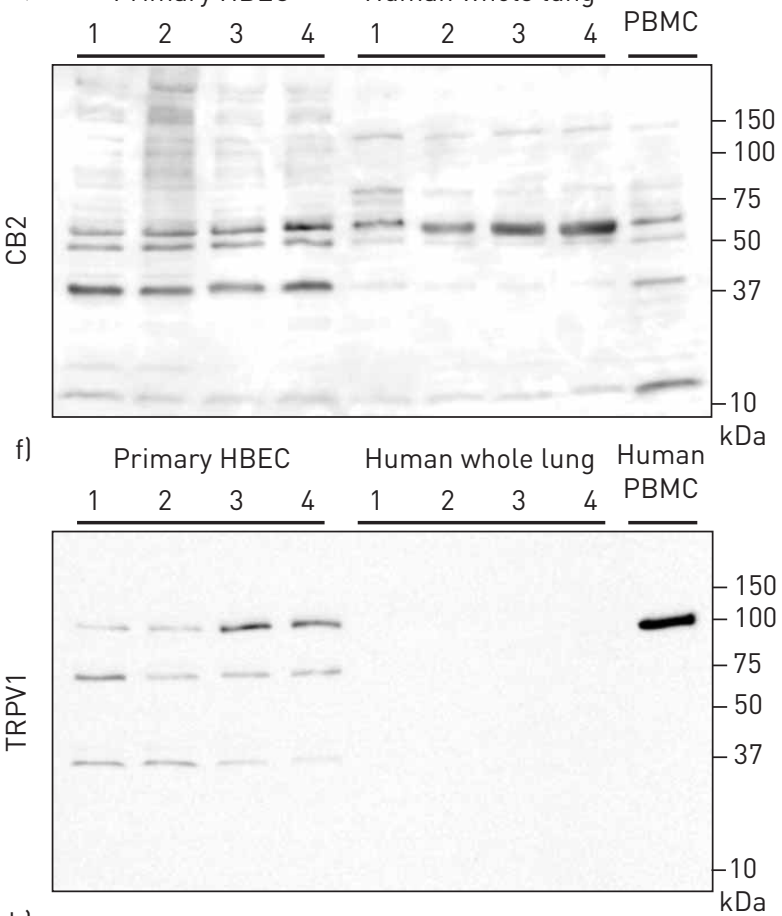

h)

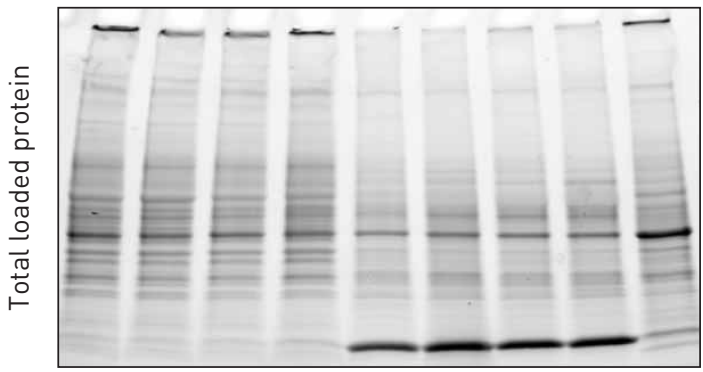

FIGURE 2 In situ and in vitro validation of $\mathrm{CB}_{1}, \mathrm{CB}_{2}$ and TRPV1 protein expression in human airway epithelial cells. Serial sections from a single patient donor that is representative of $n=10$, for immunohistochemistry of a) $\mathrm{CB}_{1}$, c) $\mathrm{CB}_{2}$ and e) TRPV1 with g) negative control. Immunoblots on primary human airway epithelial cells cultured in vitro: b) $\mathrm{CB}_{1}$, d) $\mathrm{CB}_{2}$, and f) TRPV1 with h) total protein loading control ( $\mathrm{n}=4$ airway epithelial cells (HBEC), $n=4$ whole-lung samples, $n=1$ peripheral blood mononuclear cells (PBMCs)). Molecular weights (in kilodaltons) are denoted on $y$-axis of immunoblots.

and COPD subjects, with samples from people with asthma separating from both healthy subjects and those with COPD (figure 5a). Statistical analysis at the individual gene level revealed changes in 21 of 32 genes in people with asthma and 26 of 32 genes in those with COPD (figure 5b). In people with asthma, 11 of 21 dysregulated genes were upregulated (ABCB1, ABHD6, CYP2C9, GABRA2, GNAI1, GPR55, NOS2, 


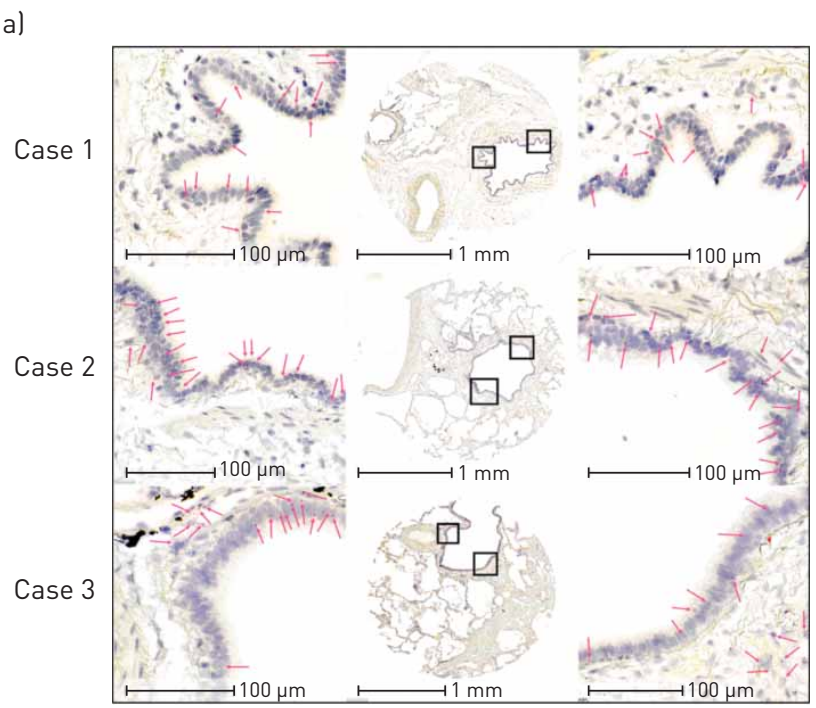

FIGURE 3 In situ hybridisation detection of CNR1 and CNR2 gene transcripts in human airway epithelial cells. In situ hybridisation of a) CNR1 and b) CNR2 in three patient donors representative of $n=10$. Serial sections of each of the three cases were stained for CNR1 and CNR2. Low magnification images are in the centre of $a$ and $b$, with high-powered magnification regions of interest on either side highlighted by black boxes. Pink arrows correspond to positive puncta representative of mRNA transcript. b)

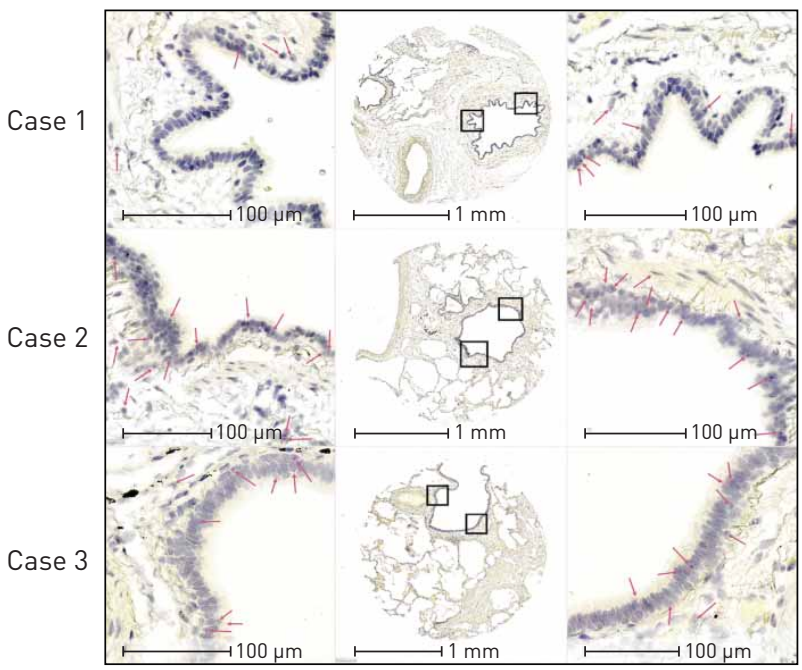

NRG1, PTGS2, TP53, and TRPV1), while 10 of 21 were downregulated (ABHD12, CNR2, COMT, CYP3A4, DAGLA, DAGLB, MAP2K2, MAPK3, MGLL, and NAAA). In COPD subjects, 11 of 26 dysregulated genes were upregulated (ABHD6, CNR1, CYP2C9, CYP3A4, FAAH, GABRA2, GPR55, NAAA, NAPEPLD, OPMRI, and TRPV1), while 15 of 26 were downregulated (ABCB1,ABHD12, ABCY3, AKT1, DAGLB, DUSP6, FAAH2, GNAI1, MAPK14, MAPK3, MGLL, NOS2, PIK3CA, PRKACA, and TP53). The most dysregulated gene was TRPV1, with the largest upregulation observed in the samples from people with asthma relative to healthy controls. The differential gene expression patterns were overlaid on the endocannabinoid signalling pathway for qualitative visualisation in asthma (figure $5 \mathrm{c}$ ) and COPD (figure 5d).

Collectively, our data demonstrate that underlying chronic respiratory disease status is associated with a dysregulation of the endocannabinoid system at the gene level in human airway epithelial cells.

Impact of sex on endocannabinoid system gene expression in human airway epithelial cells from people with asthma and those with COPD

Sex differences in incidence, age of onset, and pathology are observed in both asthma and COPD [102, 103]. Cannabinoid exposures have been explored in the context of both asthma and COPD management for immunomodulatory and bronchodilation purposes $[7,8,104]$. To date, the potential interaction of sex status and endocannabinoid system expression in chronic respiratory disease has not been addressed.

Taking the same approach as for healthy subjects, we analysed a curated dataset of airway epithelial cells from 136 unique asthmatic subjects, where the identifier of sex was available for 34 females and 28 males. 
a)

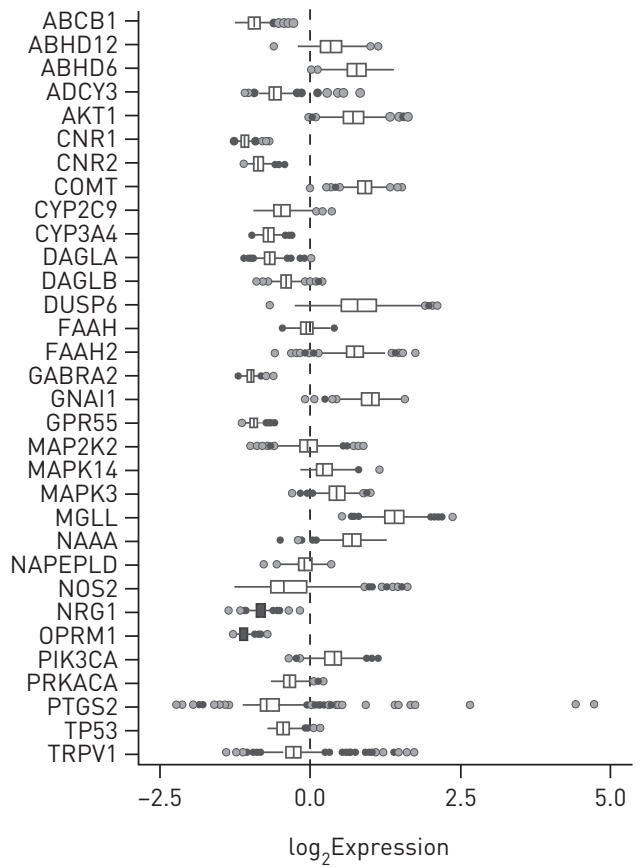

c)

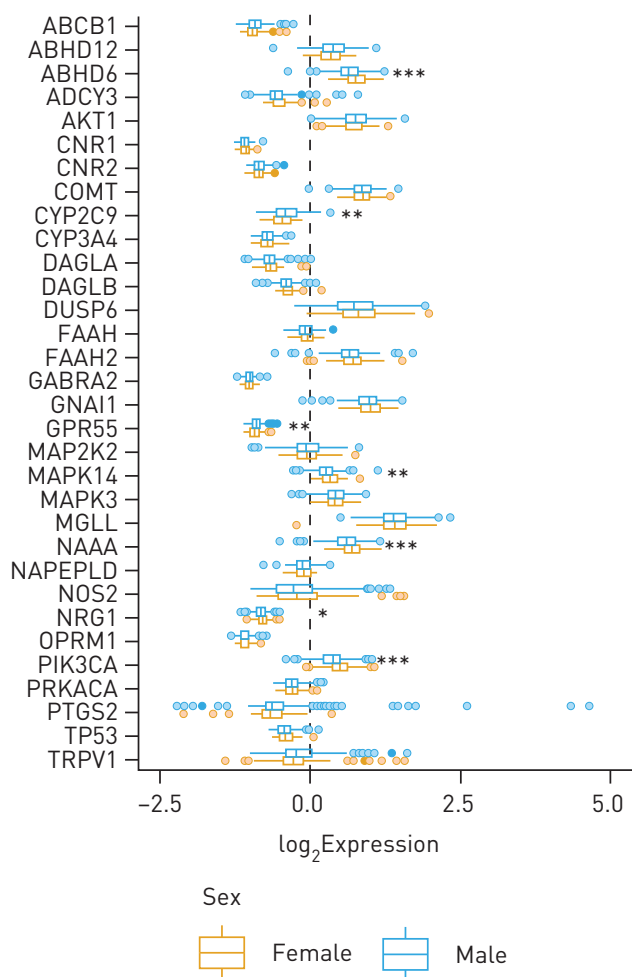

b)

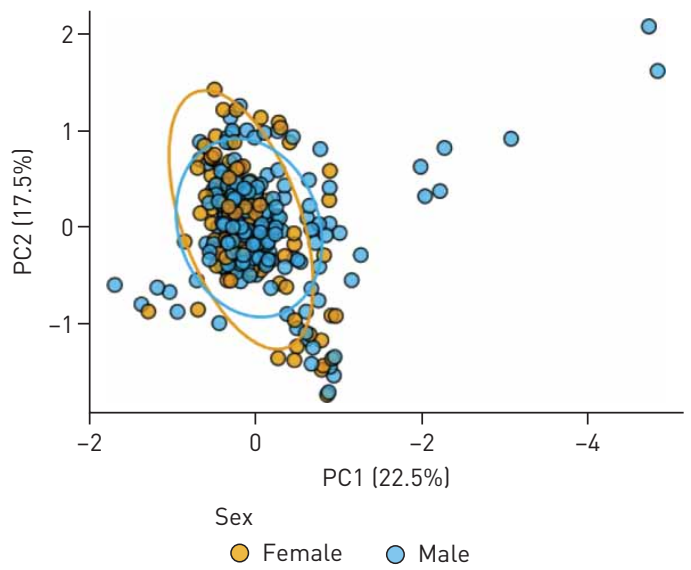

d)

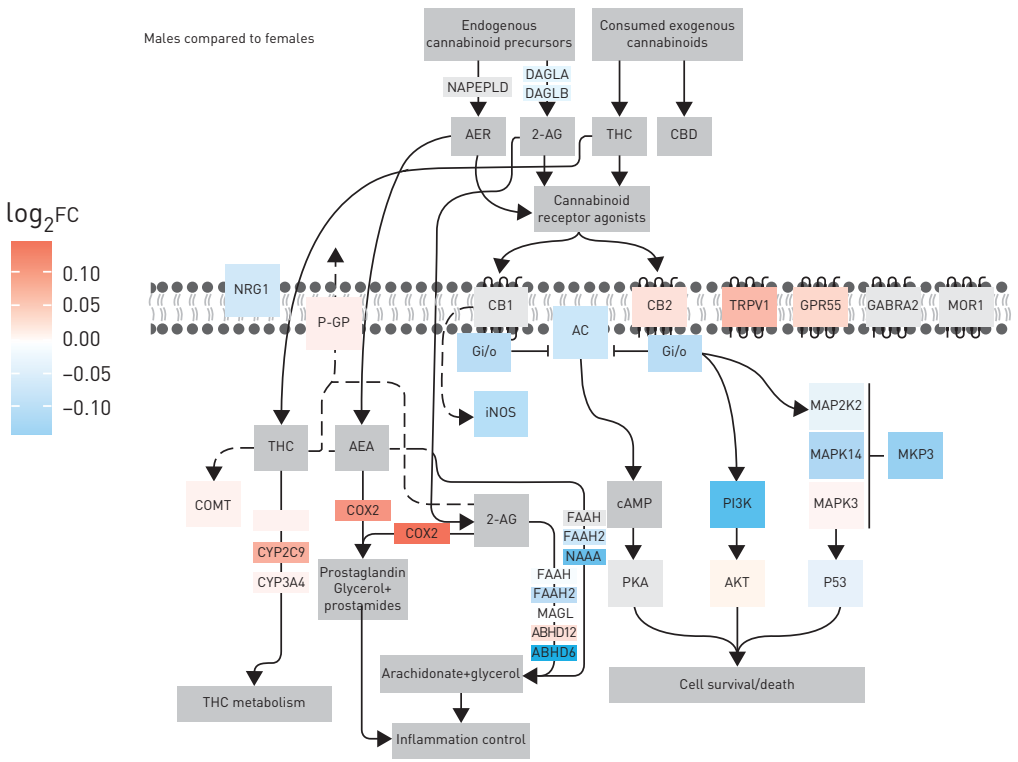

FIGURE 4 Impact of sex status on endocannabinoid system gene expression in human airway epithelial cells from healthy individuals. a) Gene expression data for 616 healthy subjects with no history of smoking or chronic respiratory disease. b) Principal-component (PC) analysis plot of healthy females $(n=103)$ and males $(n=227)$ generated by expression patterns of the 32-gene endocannabinoid signature. The first (22.5\%) and second (17.5\%) PCs were used. Ellipses were added to represent $95 \%$ confidence intervals per sex. c) Healthy samples with metadata defining sex were further divided into male and female groups and plotted separately as blue and orange-outlined box plots, respectively. For both a and $c$, $\log _{2}$-transformed expression values were plotted as box plots. The dashed line at zero represents the global baseline of expression for the entire set of genes. d) Visual representation of the differences between healthy females and males in the 32-gene endocannabinoid signature. Colour coding is reflective of $\log _{2}$ fold change of males relative to females. THC: tetrahydrocannabinol. ${ }^{*}: p<0.05 ;{ }^{* *}: p<0.01 ;{ }^{* * *}: p<0.001$. 
a)

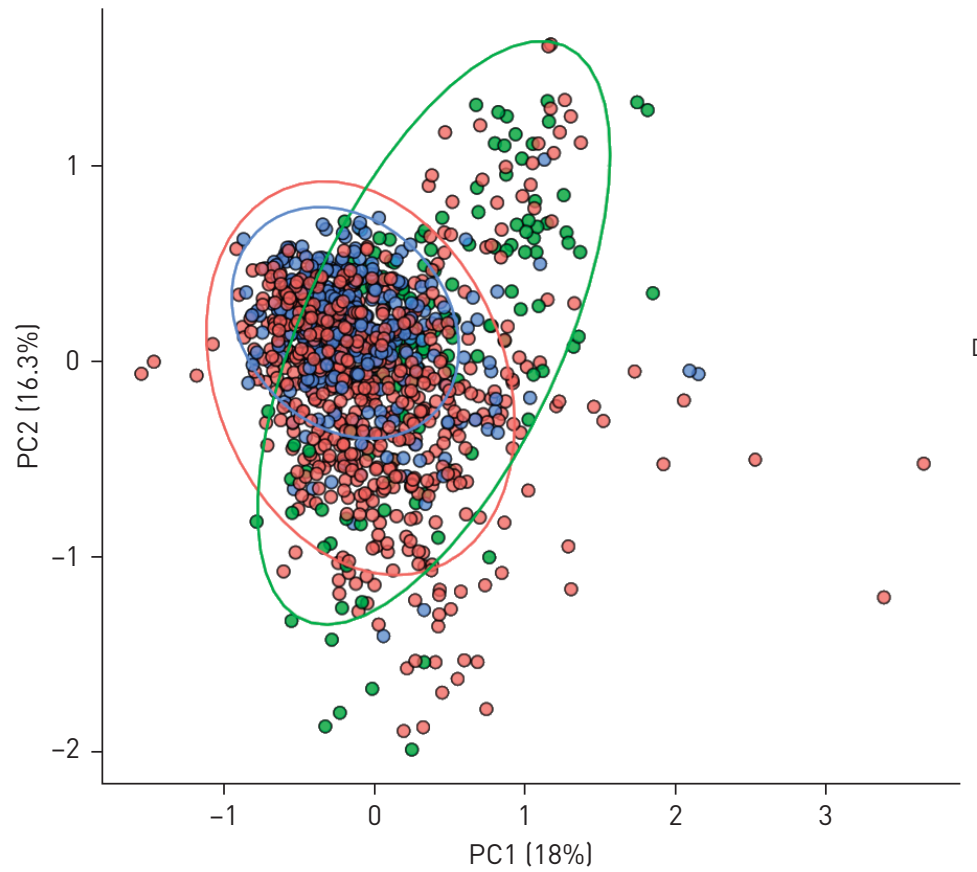

b)

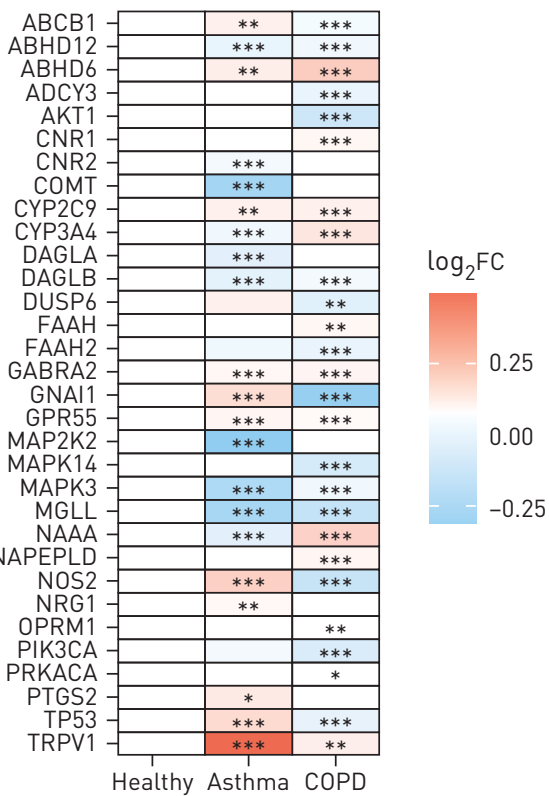

c)

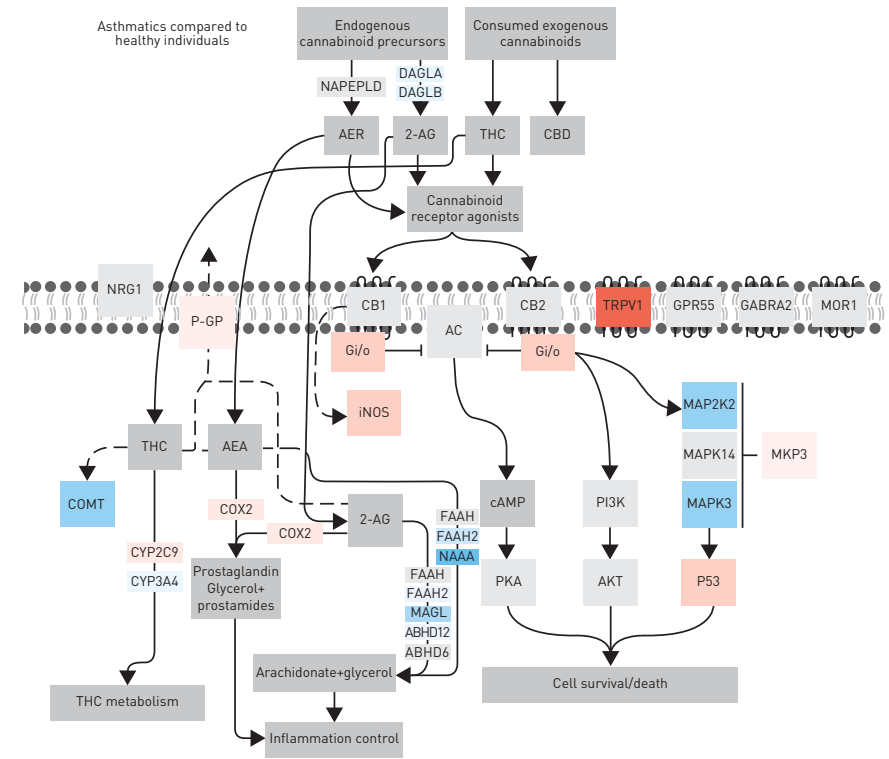

d)
Disease status

○ Healthy

- Asthma

- COPD

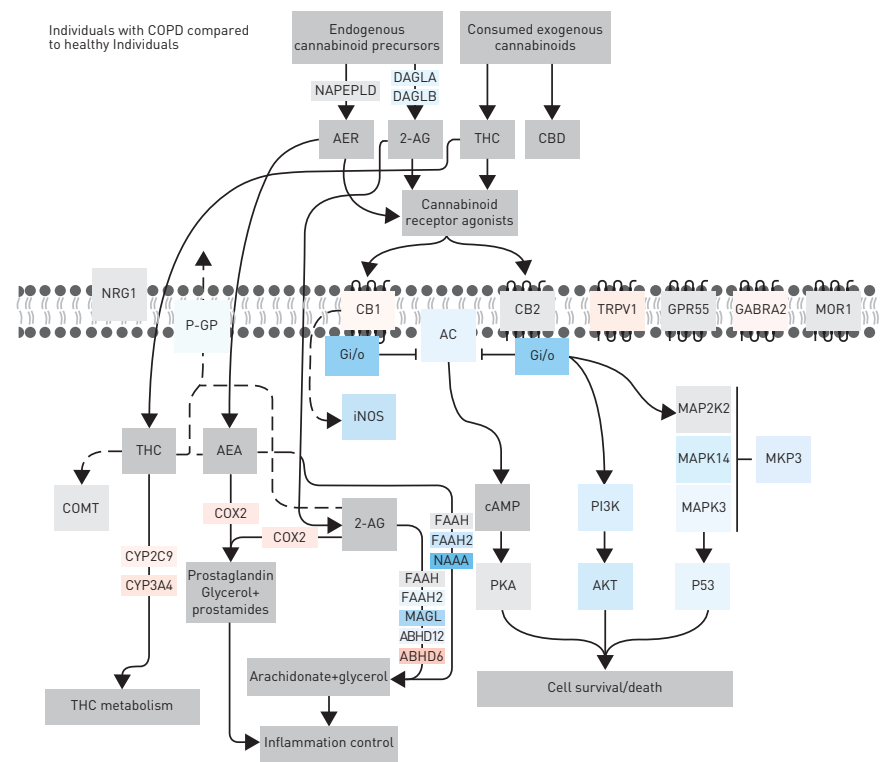

FIGURE 5 Impact of disease status on endocannabinoid system gene expression analysis in human airway epithelial cells from healthy individuals, people with asthma, and individuals with COPD. a) Principal-component (PC) analysis plot of healthy subjects ( $\mathrm{n}=616)$, people with asthma ( $\mathrm{n}=136$ ) and individuals with COPD ( $n=338$ ) generated by expression patterns of the 32 -gene endocannabinoid signature. The first (18\%) and second $(16.3 \%)$ PCs were used. Ellipses were added to represent $95 \%$ confidence intervals per sex. b) Gene expression data of the 32 genes were compared between healthy, asthmatic and COPD samples. The $\log _{2}$-transformed mean expression values were compared to that of the healthy samples and shown as $\log _{2}$ fold change (FC). Visual representation of the differences in the 32-gene endocannabinoid signature between c) healthy subjects and people with asthma and d) healthy subjects and individuals with COPD. Colour coding is reflective of log ${ }_{2} \mathrm{FC}$ relative to healthy subjects. THC: tetrahydrocannabinol. *: $p<0.05 ;{ }^{* *}: p<0.01 ;{ }^{* * *}: p<0.001$.

For COPD, we analysed a curated dataset from 338 unique COPD subjects, where the identifier of sex was available for 48 females and 93 males (see table 2 for study group compositions).

In both asthma and COPD samples, PCA plots revealed no separation between sexes with clustering of samples overlapping between disease groups (figure $6 \mathrm{a}$ and $\mathrm{c}$ ). At the individual gene level, no 


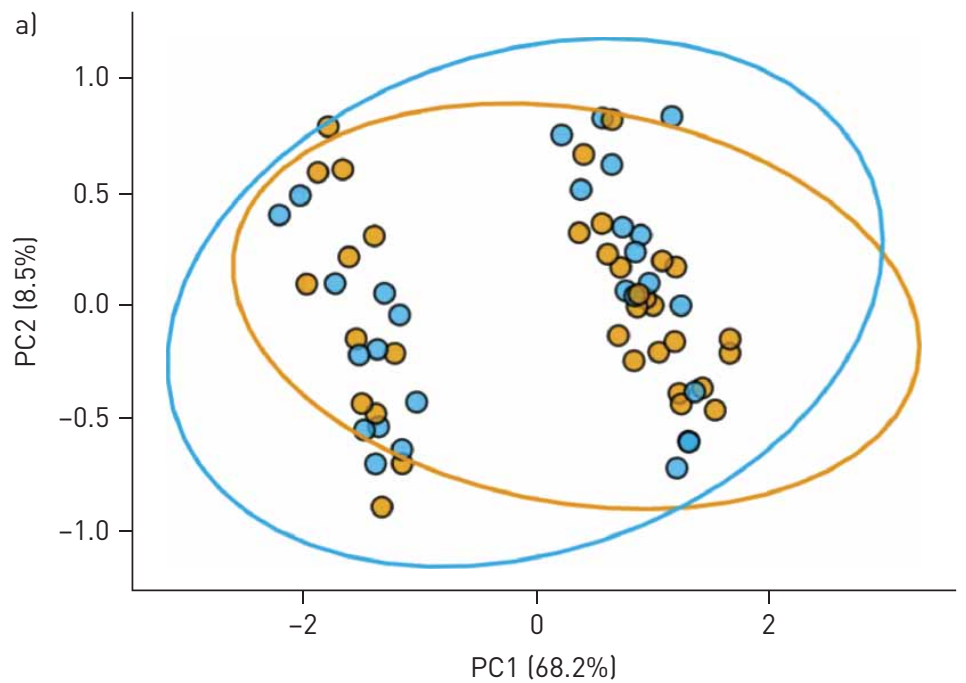

Sex

O Female O Male b)

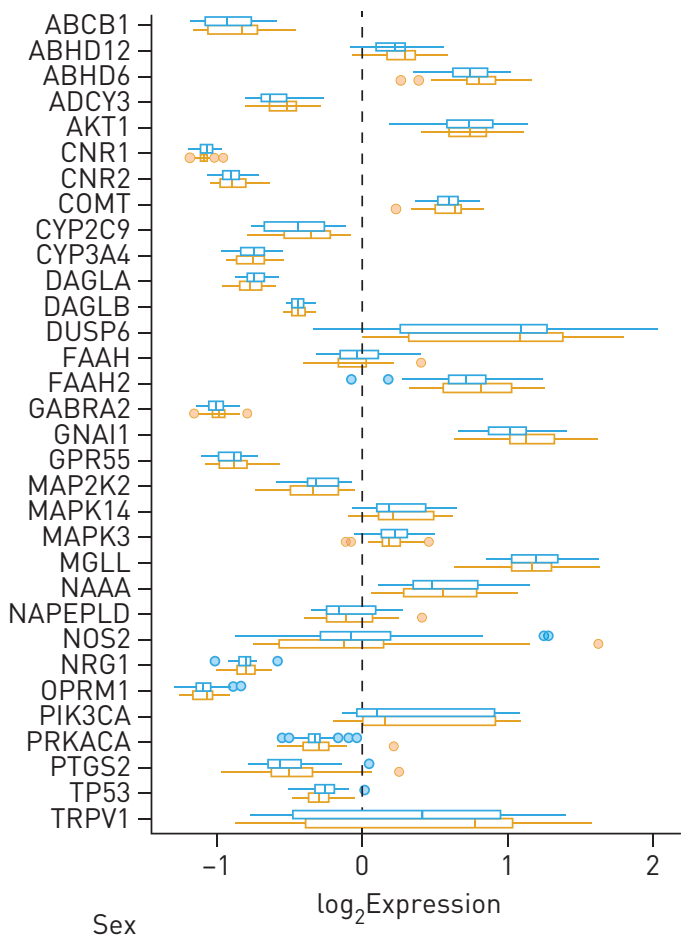

Sex

\section{Female $\square$ Male}

d)

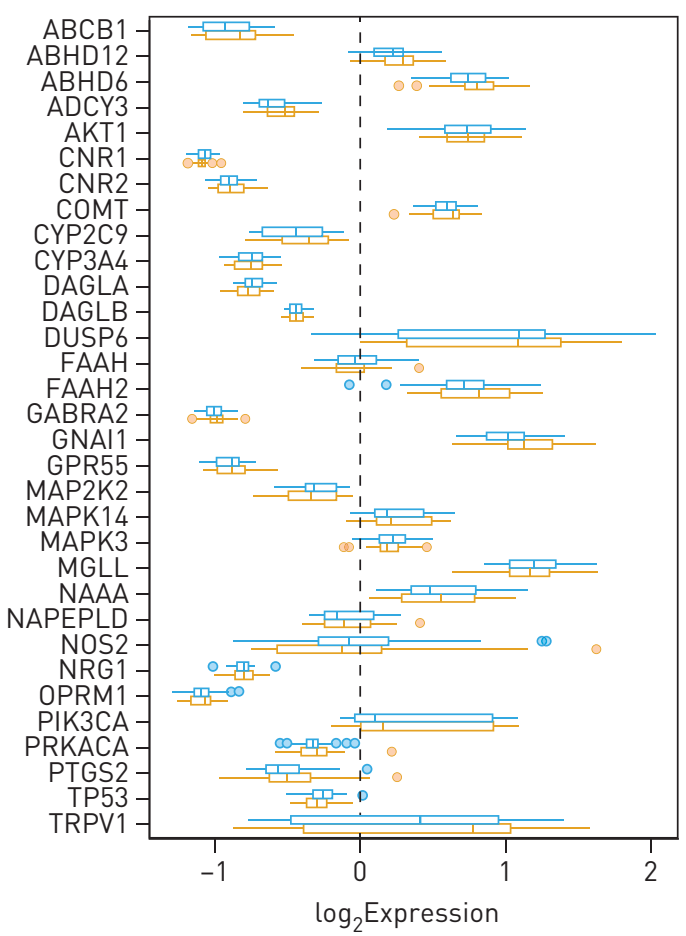

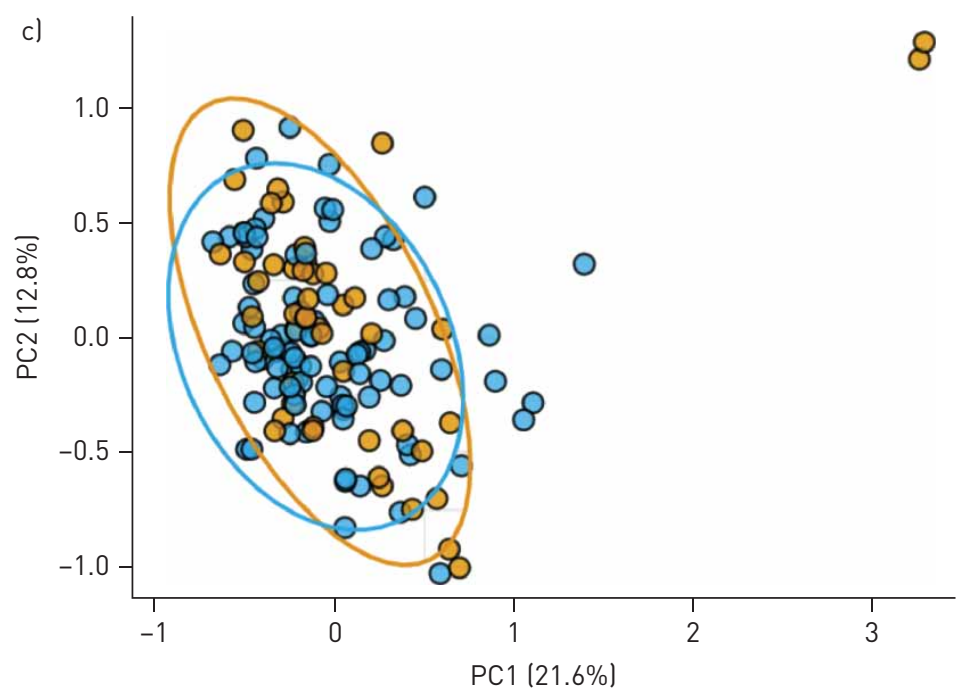

8 
sex-dependent differences were observed for any gene in the 32-gene endocannabinoid signature in either disease groups (figure $6 \mathrm{~b}$ and $\mathrm{d}$ ).

Collectively, our data do not support sex differences in the endocannabinoid system in human airway epithelial cells from people with asthma or subjects with COPD.

\section{TRPV1 is upregulated in airway epithelial cells from people with asthma}

As our bioinformatic interrogation of the 32-gene endocannabinoid signature was restricted to genes, we next performed confirmatory protein expression analysis. The candidate we chose for validation was TRPV1, a confirmed receptor for cannabinoids that was the most differentially expressed candidate between our comparisons examining sex or disease status.

Using primary human airway epithelial cells from healthy donors or those with physician-diagnosed asthma, protein was isolated from cells grown under submerged monolayer culture conditions. Immunoblot analysis confirmed TRPV1 protein expression in human airway epithelial cells and revealed an increase in cells from people with asthma (figure 7). In closing, our protein analysis is consistent with the bioinformatic analysis that revealed elevations in the TRPV1 gene in human airway epithelial cells from people with asthma.

\section{Discussion}

The dominant route of delivery of cannabis is via inhalation of combustion smoke, resulting in exposure to phytocannabinoids and activation of the endocannabinoid system [2-4]. The airway epithelium represents the first line of defence in the human lung against inhaled insults, including cannabis smoke. To better understand how the epithelium is able to respond to cannabis smoke exposure in the context of the endocannabinoid system, we performed a characterisation study using bioinformatic and complementary protein analysis approaches. We provide data supporting expression of $\mathrm{CB}_{1}, \mathrm{CB}_{2}$, and TRPV1 at the protein level in the human airway epithelium in situ and in vitro. We support our observations of protein expression by demonstrating that CNR1 and CNR2 transcripts are present in human airway epithelial cells using in situ hybridisation methods. The demonstration that these receptors were present warranted an exploration into the endocannabinoid system downstream of the receptors. Using 1090 unique patient samples of airway epithelial cells curated from publicly available datasets, we demonstrated in healthy subjects that the gene expression levels of the endocannabinoid system show

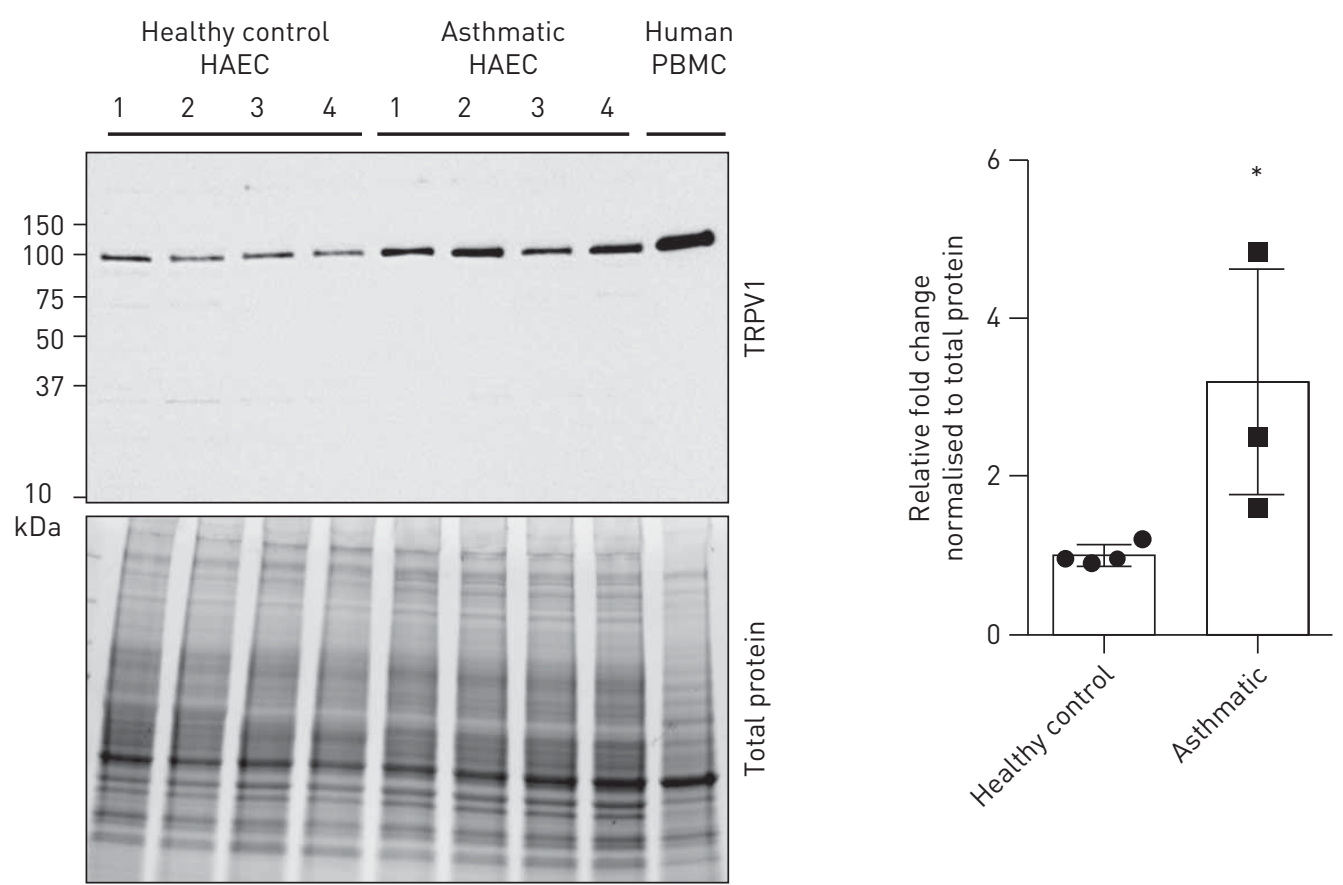

FIGURE 7 TRPV1 protein is elevated in human airway epithelial cells (HAECs) from people with asthma. Immunoblot of HAECs from healthy subjects $(n=4)$, people with asthma $(n=4)$ and peripheral blood mononuclear cell (PBMCs) (control) were analysed for TRPV1 and quantified as fold change over healthy subjects, normalised to total protein loading. *: $p<0.05$. 
minor differences between females relative to males. In contrast, we demonstrated with samples from people with asthma or individuals with COPD that disease status appears to be a strong driver of endocannabinoid system gene expression, with no interaction with sex. Lastly, we validated the bioinformatic approach by demonstrating that TRPV1, a top candidate upregulated at the gene level in our studies, is also upregulated at the protein level in people with asthma. Collectively, our results confirm the expression of the endocannabinoid system in human airway epithelial cells and that disease status impacts expression to a greater extent than sex, which may have functional consequences in distinct populations of cannabis consumers.

The legalisation of cannabis in multiple jurisdictions on a global scale reduces barriers for individuals to consume cannabis for either medicinal or recreational purposes. The dominant route of cannabis delivery is through inhalation of smoke from plant combustion [2-4]. Inhaled cannabis smoke travels through the upper and lower airways, with airway epithelial cells being a major site of first contact. We have demonstrated with an in vitro model of airway epithelial cell culture that cannabis smoke induces a concentration-dependent reduction in airway epithelial cell viability, barrier function, while promoting proinflammatory cytokine secretion [31,32]. Complementary profiling of human epithelial cells isolated via bronchial brushings has demonstrated cannabis consumption-dependent elevations in TLR5, TLR6, and TLR9 gene expression [105]. A limitation of these studies is the lack of mechanistic interrogation into the role that the endocannabinoid system contributed to the observed functional consequences of cannabis smoke. To begin to implicate the endocannabinoid system in epithelial cell functions, an in vitro approach has used direct cannabinoid administration to airway epithelial cells independent of combustion, showing functional consequences with altered barrier function mediated by mechanisms dependent and independent of cannabinoid receptors $[35,36]$. Our demonstration that multiple endocannabinoid system components are expressed at the gene level in airway epithelial cells with $\mathrm{CB}_{1}, \mathrm{CB}_{2}$, and TRPV1 confirmed at the protein level, is consistent with this system have the potential to play a role in mediating cannabis smoke-induced effects. Collectively, our data and existing literature suggest that the dominant form of cannabis consumption, cannabis smoke inhalation, is able to induce functional responses in airway epithelial cells that may be influenced by the endocannabinoid system.

Cannabis use patterns have been reported to differ among males and females, with females consuming less in overall quantity and frequency [2-4]. The endocannabinoid system is in turn regulated by sex hormones with diverse interactions at levels of receptors, enzymes, and signalling molecules [106, 107]. In the context of lung health and disease, sex-dependent lung physiology is observed as well as asthma and COPD disease incidence and progression $[102,103]$. In light of the potential for interactions between sex, user practices, and the endocannabinoid system, we performed a bioinformatic analysis that stratified for male and female sex status. In healthy individuals, we observe that only 7 of 32 of our endocannabinoid gene signature candidates were differentially regulated between males versus females ( 2 upregulated, and 5 downregulated). In our analysis, the most significant differentially expressed gene between sexes was ABHD6 (increased in female samples). Increased female expression of ABHD6 has been previously reported in immune cells, with only female cells showing oestrogen- or progesterone-dependent induction of ABHD6 gene levels [108]. Our observations of minor sex-dependent effects on the expression of the 32-gene endocannabinoid signature contrast with sex differences in the expression of $\mathrm{CB}_{1}$ and $\mathrm{CB}_{2}$ protein expression in heart tissue, where $\mathrm{CB}_{1}$ receptors are more highly expressed in females and $\mathrm{CB}_{2}$ receptors more highly expressed in males [98]. Our observations of limited impact of sex on the 32-gene endocannabinoid signature expression in healthy subjects were conserved in people with asthma and individuals with COPD. In contrast to sex status, disease status drove a large effect for differential expression of the 32-gene endocannabinoid signature, with the majority of genes dysregulated (21 of 32 genes in people with asthma and 26 of 32 genes in those with COPD). Collectively, these findings suggest that asthma or COPD status impacts expression of the endocannabinoid system, whereas sex status plays a comparatively smaller role.

The potential disease-specific response to cannabis exposure as a result of dysregulated endocannabinoid signalling is relevant as cannabinoids have and are being pursued for bronchodilatory and immunomodulatory properties $[7,8,104,109]$. Furthermore, in populations of people with asthma and those with COPD, cannabis consumption is not avoided and is shown to interact with disease progression. The reported benefits of cannabis exposure on lung function in people with asthma may be selective for this population based on endocannabinoid signalling. Indeed, if TRPV1 is a dominant receptor for responses downstream of inhaled cannabis, the signalling mediated in airway epithelial cells from people with asthma may be augmented relative to healthy controls. Our observation of elevated TRPV1 in airway epithelial cells from people with asthma is consistent with a previous report demonstrating correlation with asthma severity [110]. A limitation of our study is that we did not explore other cell types for TRPV1, which is also expressed in airway smooth muscle cells and can modulate smooth muscle 
contraction [111]. In contrast, the lack of observed benefit on lung function and association with advanced pathology in COPD subjects may be a result of a distinct expression profile of the endocannabinoid system $[10,11,104]$. Our results and those in the literature suggest that a universal response to inhaled cannabis by healthy subjects and those with asthma or COPD should not be assumed and cautions translation of safety and efficacy studies performed in healthy individuals to those with underlying asthma or COPD.

Our study is heavily focused on using deposited datasets generated by microarray gene expression technology. Microarrays are low cost, cover large numbers of transcripts, and benefit from a standardised format for analysis and public deposition of data. As a result of these benefits, gene expression data for large, independent cohorts are available for curation and data-mining purposes if appropriate measures are taken to normalise and integrate datasets from diverse user groups. Despite benefits of curated microarray datasets, there exist limitations of our approach. Specifically, microarray technology is susceptible to a poor signal-to-noise ratio, making transcripts expressed at low levels difficult to detect, suggesting that we may be under-estimating the signal or introducing high variance of these transcripts. To address this limitation, the SCAN method deployed functions to reduce technical and across-sample variation and to increase the signal-to-noise ratio while maintaining the ability to detect differentially expressed genes [91]. As in all analyses, the sample size will dictate the statistical power, which can only be as large as the available datasets. In our case, the sample sizes for females and males in our asthma and COPD datasets were smaller than our healthy cohorts, which may have limited our ability to detect any sex-specific effects on endocannabinoid gene expression. Finally, in order to compare data across multiple experiments, the microarray chip technology used needs to be considered with additional normalisation methods required for data generated on different platforms. Different microarray technologies will have unique probe compositions and quality control protocols which can lead to systematic biases between experiments, though these batch-specific effects can be addressed using batch correction techniques and normalisation [112]. Despite these highlighted limitations, the curation of multiple microarray gene expression datasets from diverse cohorts of study subjects can be aligned with normalisation methods to minimise batch and cross-platform effects and maximising sample sizes to detect differential gene expression patterns.

The advances of our study are accompanied by several limitations that need to be discussed. All analyses performed used human lung samples or datasets that did not contain information on cannabis consumption practices of the study subjects or body mass index, and we did not stratify by age. Furthermore, we broadly categorised people with asthma and COPD without stratifying by disease severity. It is possible that cannabis consumption impacts the expression of endocannabinoid system components examined in our study, a possibility we are not able to interrogate. Related to this possibility, a key finding of our study is the elevation of TRPV1 in people with asthma, which may be regulated differently with and without cannabis exposure [59]. Future studies examining healthy subjects and those with asthma or COPD in the context of cannabis exposure will address this limitation. We also only focused on airway epithelial cells, a dominant aspect of the respiratory mucosal defence system in the lungs. Observations in airway epithelial cells may be cell-specific and not translate to other structural or immune cells. Lastly, our archived human lung tissue samples used for immunohistochemistry and in situ hybridisation were collected from noninvolved regions of the lung taken during resection in individuals undergoing surgery as part of lung cancer management. It is possible that the underlying status of lung cancer impacts the expression profiling of the endocannabinoid system. Our analysis of nonlung cancer microarray datasets and immunoblot confirmation using healthy and diseased (asthma) samples attempted to corroborate observations made from the samples taken during lung resections.

In summary, we demonstrate that endocannabinoid system components are expressed in human airway epithelial cells at the gene level and $\mathrm{CB}_{1}, \mathrm{CB}_{2}$, and TRPV1 are expressed at the protein level. We demonstrate that gene expression patterns for a 32-gene endocannabinoid signature are differentially expressed between healthy individuals and those with asthma or COPD, whereas only minor differences are observed between sexes. We confirm that our bioinformatic approach for analysis of gene expression has the potential to reflect corresponding protein expression level changes as demonstrated by elevated TRPV1 protein expression in human airway epithelial cells from people with asthma relative to healthy controls. Our study lays a foundation with primary human lung samples from well-defined patient populations to justify exploring the functional consequences of endocannabinoid system signalling in human airway epithelial cells in both health and disease. The complete functions of the endocannabinoid system in airway epithelial cells remain to be defined.

Acknowledgements: The authors acknowledge Olivia Marcello (freelance graphic artist) for her help in figure design. Additionally, the authors acknowledge James MacKillop and Allan Fein (Centre for Medicinal Cannabis Research at McMaster University) for administrative support, and graduate student stipend support (M.F. Fantauzzi and A. Chandiramohan) from the Centre for Medicinal Cannabis Research at McMaster University. 
Data availability: All data are available upon request.

Support statement: This work was supported by the McMaster Centre for Medicinal Cannabis Research and the Ontario Lung Association. Funding information for this article has been deposited with the Crossref Funder Registry.

Conflict of interest: None declared.

\section{References}

$1 \quad$ World Health Organization. World Drug Report 2018. United Nations publication SNEX.

2 Health Canada. The Cannabis Survey: Methodological Report. http://epe.lac-bac.gc.ca/100/200/301/pwgsc-tpsgc/ por-ef/health/2017/102-16-e/index.html Date last accessed: November 24, 2020. Date last updated: November 24 20202017.

3 Health Canada. Canadian Cannabis Survey. http://epe.lac-bac.gc.ca/100/200/301/pwgsc-tpsgc/por-ef/health/2018/ 006-18-e/index.html Date last accessed: November 24, 2020. Date last updated: November 24, 20202018.

4 Health Canada. Canadian Cannabis Survey. https://www.canada.ca/en/health-canada/services/publications/drugshealth-products/canadian-cannabis-survey-2019-summary.html Date last accessed: November 24, 2020. Date last updated: November 24, 20202019.

5 Vachon L, FitzGerald MX, Solliday NH, et al. Single-dose effects of marihuana smoke. Bronchial dynamics and respiratory-center sensitivity in normal subjects. N Engl J Med 1973; 288: 985-989.

6 Tashkin DP, Shapiro BJ, Frank IM. Acute pulmonary physiologic effects of smoked marijuana and oral (Delta) 9 -tetrahydrocannabinol in healthy young men. N Engl J Med 1973; 289: 336-341.

7 Tashkin DP, Shapiro BJ, Frank IM. Acute effects of smoked marijuana and oral delta9-tetrahydrocannabinol on specific airway conductance in asthmatic subjects. Am Rev Respir Dis 1974; 109: 420-428.

8 Tashkin DP, Shapiro BI, Lee YE, et al. Effects of smoked marijuana in experimentally induced asthma. Am Rev Respir Dis 1975; 112: 377-386.

9 Tashkin DP, Shapiro BJ, Lee YE, et al. Subacute effects of heavy marihuana smoking on pulmonary function in healthy men. N Engl J Med 1976; 294: 125-129.

10 Tan WC, Bourbeau J, Aaron SD, et al. The effects of marijuana smoking on lung function in older people. Eur Respir J 2019; 54: 1900826.

11 Tan WC, Lo C, Jong A, et al. Marijuana and chronic obstructive lung disease: a population-based study. CMAJ 2009; 180: 814-820.

12 Fligiel SE, Roth MD, Kleerup EC, et al. Tracheobronchial histopathology in habitual smokers of cocaine, marijuana, and/or tobacco. Chest 1997; 112: 319-326.

13 Gong H Jr, Fligiel S, Tashkin DP, et al. Tracheobronchial changes in habitual, heavy smokers of marijuana with and without tobacco. Am Rev Respir Dis 1987; 136: 142-149.

14 Roth MD, Arora A, Barsky SH, et al. Airway inflammation in young marijuana and tobacco smokers. Am J Respir Crit Care Med 1998; 157: 928-937.

15 Hancox RJ, Shin HH, Gray AR, et al. Effects of quitting cannabis on respiratory symptoms. Eur Respir J 2015; 46: 80-87.

16 Baldwin GC, Tashkin DP, Buckley DM, et al. Marijuana and cocaine impair alveolar macrophage function and cytokine production. Am J Respir Crit Care Med 1997; 156: 1606-1613

17 Calignano A, Katona I, Desarnaud F, et al. Bidirectional control of airway responsiveness by endogenous cannabinoids. Nature 2000; 408: 96-101.

18 Grassin-Delyle S, Naline E, Buenestado A, et al. Cannabinoids inhibit cholinergic contraction in human airways through prejunctional CB1 receptors. Br J Pharmacol 2014; 171: 2767-2777.

19 Turcotte C, Blanchet MR, Laviolette M, et al. Impact of cannabis, cannabinoids, and endocannabinoids in the lungs. Front Pharmacol 2016; 7: 317.

20 Devane WA, Hanus L, Breuer A, et al. Isolation and structure of a brain constituent that binds to the cannabinoid receptor. Science 1992; 258: 1946-1949.

21 Stella N, Schweitzer P, Piomelli D. A second endogenous cannabinoid that modulates long-term potentiation. Nature 1997; 388: 773-778.

22 Pertwee RG, Howlett AC, Abood ME, et al. International Union of Basic and Clinical Pharmacology. LXXIX. Cannabinoid receptors and their ligands: beyond $\mathrm{CB}(1)$ and $\mathrm{CB}(2)$. Pharmacol Rev 2010; 62: 588-631.

23 Matsuda LA, Lolait SJ, Brownstein MJ, et al. Structure of a cannabinoid receptor and functional expression of the cloned cDNA. Nature 1990; 346: 561-564.

24 Munro S, Thomas KL, Abu-Shaar M. Molecular characterization of a peripheral receptor for cannabinoids. Nature 1993; 365: 61-65.

25 Zygmunt PM, Petersson J, Andersson DA, et al. Vanilloid receptors on sensory nerves mediate the vasodilator action of anandamide. Nature 1999; 400: 452-457.

26 Ryberg E, Larsson N, Sjogren S, et al. The orphan receptor GPR55 is a novel cannabinoid receptor. $\mathrm{Br}$ Pharmacol 2007; 152: 1092-1101.

27 Hiemstra PS, McCray PB Jr, Bals R. The innate immune function of airway epithelial cells in inflammatory lung disease. Eur Respir J 2015; 45: 1150-1162.

28 Hirota JA, Knight DA. Human airway epithelial cell innate immunity: relevance to asthma. Curr Opin Immunol 2013; 24: 740-746.

29 Parker D, Prince A. Innate immunity in the respiratory epithelium. Am J Respir Cell Mol Biol 2011; 45: 189-201.

30 Huff RD, Carlsten C, Hirota JA. An update on immunologic mechanisms in the respiratory mucosa in response to air pollutants. J Allergy Clin Immunol 2019; 143: 1989-2001.

31 Aguiar JA, Huff RD, Tse W, et al. Transcriptomic and barrier responses of human airway epithelial cells exposed to cannabis smoke. Physiol Rep 2019; 7: e14249.

32 Huff RD, Aguiar JA, Tse W, et al. Effect of long-acting $\beta$-agonists/glucocorticoids on human airway epithelial cell cytokine, transcriptomic and oxidative stress responses to cannabis smoke. ERJ Open Res 2020; 6: 00265-2019. 
Galiegue S, Mary S, Marchand J, et al. Expression of central and peripheral cannabinoid receptors in human immune tissues and leukocyte subpopulations. Eur J Biochem 1995; 232: 54-61.

Corrado A, Battle M, Wise SK, et al. Endocannabinoid receptor CB2R is significantly expressed in aspirin-exacerbated respiratory disease: a pilot study. Int Forum Allergy Rhinol 2018; 8: 1184-1189.

Shang VC, Kendall DA, Roberts RE. Delta(9)-tetrahydrocannabinol reverses TNF- $\alpha$-induced increase in airway epithelial cell permeability through CB2 receptors. Biochem Pharmacol 2016; 120: 63-71.

Shang VC, O'Sullivan SE, Kendall DA, et al. The endogenous cannabinoid anandamide increases human airway epithelial cell permeability through an arachidonic acid metabolite. Pharmacol Res 2016; 105: 152-163.

Gurtler A, Kunz N, Gomolka M, et al. Stain-free technology as a normalization tool in western blot analysis Anal Biochem 2013; 433: 105-111.

Agrawal A, Lynskey MT. Candidate genes for cannabis use disorders: findings, challenges and directions. Addiction 2009; 104: 518-532.

Blankman JL, Simon GM, Cravatt BE. A comprehensive profile of brain enzymes that hydrolyze the endocannabinoid 2-arachidonoylglycerol. Chem Biol 2007; 14: 1347-1356.

Marrs WR, Blankman JL, Horne EA, et al. The serine hydrolase ABHD6 controls the accumulation and efficacy of 2-AG at cannabinoid receptors. Nat Neurosci 2010; 13: 951-957.

Physiol Rev 2009; 89: 309-380.

Galve-Roperh I, Rueda D, Gomez del Pulgar T, et al. Mechanism of extracellular signal-regulated kinase activation by the CB(1) cannabinoid receptor. Mol Pharmacol 2002; 62: 1385-1392.

Henquet C, Rosa A, Krabbendam L, et al. An experimental study of catechol-o-methyltransferase Val158Met moderation of delta-9-tetrahydrocannabinol-induced effects on psychosis and cognition. Neuropsychopharmacology 2006; 31: 2748-2757.

Watanabe K, Yamaori S, Funahashi T, et al. Cytochrome P450 enzymes involved in the metabolism of tetrahydrocannabinols and cannabinol by human hepatic microsomes. Life Sci 2007; 80: 1415-1419.

Powles T, te Poele R, Shamash J, et al. Cannabis-induced cytotoxicity in leukemic cell lines: the role of the cannabinoid receptors and the MAPK pathway. Blood 2005; 105: 1214-1221.

Kathuria S, Gaetani S, Fegley D, et al. Modulation of anxiety through blockade of anandamide hydrolysis. Nat Med 2003; 9: 76-81.

Onwuameze OE, Nam KW, Epping EA, et al. MAPK14 and CNR1 gene variant interactions: effects on brain volume deficits in schizophrenia patients with marijuana misuse. Psychol Med 2013; 43: 619-631.

Bosier B, Lambert DM, Hermans E. Reciprocal influences of CB1 cannabinoid receptor agonists on ERK and JNK signalling in N1E-115 cells. FEBS Lett 2008; 582: 3861-3867.

Dinh TP, Carpenter D, Leslie FM, et al. Brain monoglyceride lipase participating in endocannabinoid inactivation. Proc Natl Acad Sci USA 2002; 99: 10819-10824.

Cinar R, Iyer MR, Liu Z, et al. Hybrid inhibitor of peripheral cannabinoid-1 receptors and inducible nitric oxide synthase mitigates liver fibrosis. JCI insight 2016; 1: e87336.

Castillo PE, Younts TJ, Chavez AE, et al. Endocannabinoid signaling and synaptic function. Neuron 2012; 76 : $70-81$.

Ruhaak LR, Felth J, Karlsson PC, et al. Evaluation of the cyclooxygenase inhibiting effects of six major cannabinoids isolated from Cannabis sativa. Biol Pharm Bull 2011; 34: 774-778.

Kebir O, Lafaye G, Blecha L, et al. ABCB1 C3435 T polymorphism is associated with tetrahydrocannabinol blood levels in heavy cannabis users. Psychiatry Res 2018; 262: 357-358.

Bondar A, Lazar J. The G protein Gil exhibits basal coupling but not preassembly with G protein-coupled receptors. J Biol Chem 2017; 292: 9690-9698.

Pharmacokinet 2018; 43: 1-12.

Kim HR, Son BH, Lee SY, et al. The role of p53 in marijuana smoke condensates-induced genotoxicity and apoptosis. Environ Health Toxicol 2012; 27: e2012017.

Carey CE, Agrawal A, Zhang B, et al. Monoacylglycerol lipase (MGLL) polymorphism rs604300 interacts with childhood adversity to predict cannabis dependence symptoms and amygdala habituation: evidence from an endocannabinoid system-level analysis. J Abnorm Psychol 2015; 124: 860-877.

Sirrs S, van Karnebeek CD, Peng X, et al. Defects in fatty acid amide hydrolase 2 in a male with neurologic and psychiatric symptoms. Orphanet J Rare Dis 2015; 10: 38.

De Petrocellis L, Ligresti A, Moriello AS, et al. Effects of cannabinoids and cannabinoid-enriched cannabis extracts on TRP channels and endocannabinoid metabolic enzymes. Br J Pharmacol 2011; 163: 1479-1494.

Zhang H, Hilton DA, Hanemann CO, et al. Cannabinoid receptor and $\mathrm{N}$-acyl phosphatidylethanolamine phospholipase D: evidence for altered expression in multiple sclerosis. Brain Pathol 2011; 21: 544-557.

Woodruff PG, Boushey HA, Dolganov GM, et al. Genome-wide profiling identifies epithelial cell genes associated with asthma and with treatment response to corticosteroids. Proc Natl Acad Sci USA 2007; 104: 15858-15863.

Woodruff PG, Modrek B, Choy DF, et al. T-helper type 2-driven inflammation defines major subphenotypes of asthma. Am J Respir Crit Care Med 2009; 180: 388-395.

Harvey BG, Heguy A, Leopold PL, et al. Modification of gene expression of the small airway epithelium in response to cigarette smoking. J Mol Med 2007; 85: 39-53.

Tilley AE, Harvey BG, Heguy A, et al. Down-regulation of the notch pathway in human airway epithelium in association with smoking and chronic obstructive pulmonary disease. Am J Respir Crit Care Med 2009; 179: 457-466.

5 Carolan BJ, Heguy A, Harvey BG, et al. Up-regulation of expression of the ubiquitin carboxyl-terminal hydrolase L1 gene in human airway epithelium of cigarette smokers. Cancer Res 2006; 66: 10729-10740.

Ammous Z, Hackett NR, Butler MW, et al. Variability in small airway epithelial gene expression among normal smokers. Chest 2008; 133: 1344-1353.

Carolan BJ, Harvey BG, De BP, et al. Decreased expression of intelectin 1 in the human airway epithelium of smokers compared to nonsmokers. J Immunol 2008; 181: 5760-5767. 
Tilley AE, O'Connor TP, Hackett NR, et al. Biologic phenotyping of the human small airway epithelial response to cigarette smoking. PLoS ONE 2011; 6: e22798.

Raman T, O'Connor TP, Hackett NR, et al. Quality control in microarray assessment of gene expression in human airway epithelium. BMC Genomics 2009; 10: 493.

Carolan BJ, Harvey BG, Hackett NR, et al. Disparate oxidant gene expression of airway epithelium compared to alveolar macrophages in smokers. Respir Res 2009; 10: 111.

Turetz ML, O'Connor TP, Tilley AE, et al. Trachea epithelium as a "canary" for cigarette smoking-induced biologic phenotype of the small airway epithelium. Clin Transl Sci 2009; 2: 260-272.

Schembri F, Sridhar S, Perdomo C, et al. MicroRNAs as modulators of smoking-induced gene expression changes in human airway epithelium. Proc Natl Acad Sci USA 2009; 106: 2319-2324.

Wang G, Wang R, Ferris B, et al. Smoking-mediated up-regulation of GAD67 expression in the human airway epithelium. Respir Res 2010; 11: 150.

Strulovici-Barel Y, Omberg L, O'Mahony M, et al. Threshold of biologic responses of the small airway epithelium to low levels of tobacco smoke. Am J Respir Crit Care Med 2010; 182: 1524-1532.

Shaykhiev R, Otaki F, Bonsu P, et al. Cigarette smoking reprograms apical junctional complex molecular architecture in the human airway epithelium in vivo. Cell Mol Life Sci 2011; 68: 877-892.

Butler MW, Fukui T, Salit J, et al. Modulation of cystatin A expression in human airway epithelium related to genotype, smoking, COPD, and lung cancer. Cancer Res 2011; 71: 2572-2581. smokers and non-smokers. BMC Med Genomics 2012; 5: 21.

Boudewijn IM, Faiz A, Steiling K, et al. Nasal gene expression differentiates COPD from controls and overlaps bronchial gene expression. Respir Res 2017; 18: 213.

Gao C, Tignor NL, Salit J, et al. HEFT: eQTL analysis of many thousands of expressed genes while simultaneously controlling for hidden factors. Bioinformatics 2014; 30: 369-376.

Buro-Auriemma LJ, Salit J, Hackett NR, et al. Cigarette smoking induces small airway epithelial epigenetic changes with corresponding modulation of gene expression. Hum Mol Genet 2013; 22: 4726-4738.

Hessel J, Heldrich J, Fuller J, et al. Intraflagellar transport gene expression associated with short cilia in smoking and COPD. PLoS ONE 2014; 9: e85453.

Walters MS, De BP, Salit J, et al. Smoking accelerates aging of the small airway epithelium. Respir Res 2014; 15: 94. Yang J, Zuo WL, Fukui T, et al. Smoking-dependent distal-to-proximal repatterning of the adult human small airway epithelium. Am J Respir Crit Care Med 2017; 196: 340-352.

Christenson SA, Steiling K, van den Berge M, et al. Clinical relevance of genomic signatures of type 2 inflammation in chronic obstructive pulmonary disease. Am J Respir Crit Care Med 2015; 191: 758-766.

Zhou H, Brekman A, Zuo WL, et al. POU2AF1 functions in the human airway epithelium to regulate expression of host defense genes. J Immunol 2016; 196: 3159-3167.

Walters MS, Salit J, Ju JH, et al. Waterpipe smoking induces epigenetic changes in the small airway epithelium. PLoS ONE 2017; 12: e0171112.

Billatos E, Faiz A, Gesthalter Y, et al. Impact of acute exposure to cigarette smoke on airway gene expression. Physiol Genomics 2018; 50: 705-713.

O'Beirne SL, Shenoy SA, Salit J, et al. Ambient pollution-related reprogramming of the human small airway epithelial transcriptome. Am J Respir Crit Care Med 2018; 198: 1413-1422.

Davis S, Meltzer PS. GEOquery: a bridge between the Gene Expression Omnibus (GEO) and BioConductor. Bioinformatics 2007; 23: 1846-1847.

Dai M, Wang P, Boyd $\mathrm{AD}$, et al. Evolving gene/transcript definitions significantly alter the interpretation of GeneChip data. Nucleic Acids Res 2005; 33: e175. personalized-medicine workflows. Genomics 2012; 100: 337-344.

Huber W, Carey VJ, Gentleman R, et al. Orchestrating high-throughput genomic analysis with Bioconductor. Nat Methods 2015; 12: 115-121.

Johnson WE, Li C, Rabinovic A. Adjusting batch effects in microarray expression data using empirical Bayes methods. Biostatistics 2007; 8: 118-127.

Leek JT, Johnson WE, Parker HS, et al. The sva package for removing batch effects and other unwanted variation in high-throughput experiments. Bioinformatics 2012; 28: 882-883.

Cheadle C, Vawter MP, Freed WJ, et al. Analysis of microarray data using Z score transformation. J Mol Diagn 2003; 5: 73-81.

Stacklies W, Redestig H, Scholz M, et al. pcaMethods--a bioconductor package providing PCA methods for incomplete data. Bioinformatics 2007; 23: 1164-1167.

Zhang R, Kim TK, Qiao ZH, et al. Biochemical and mass spectrometric characterization of the human CB2 cannabinoid receptor expressed in Pichia pastoris--importance of correct processing of the N-terminus. Protein Exp Purif 2007; 55: 225-235.

Piotrowska Z, Niezgoda M, Lebkowski W, et al. Sex differences in distribution of cannabinoid receptors (CB1 and CB2), S100A6 and CacyBP/SIP in human ageing hearts. Biol Sex Differ 2018; 9: 50.

Kicic A, Sutanto EN, Stevens PT, et al. Intrinsic biochemical and functional differences in bronchial epithelial cells of children with asthma. Am J Respir Crit Care Med 2006; 174: 1110-1118.

Steiling K, van den Berge M, Hijazi K, et al. A dynamic bronchial airway gene expression signature of chronic obstructive pulmonary disease and lung function impairment. Am J Respir Crit Care Med 2013; 187: 933-942.

Kuo CS, Pavlidis S, Loza M, et al. A Transcriptome-driven analysis of epithelial brushings and bronchial biopsies to define asthma phenotypes in U-BIOPRED. Am J Respir Crit Care Med 2017; 195: 443-455.

Postma DS. Gender differences in asthma development and progression. Gend Med 2007; 4: Suppl. B, S133-S146. Sorheim IC, Johannessen A, Gulsvik A, et al. Gender differences in COPD: are women more susceptible to smoking effects than men? Thorax 2010; 65: 480-485.

Abdallah SJ, Smith BM, Ware MA, et al. Effect of vaporized cannabis on exertional breathlessness and exercise endurance in advanced chronic obstructive pulmonary disease. A randomized controlled trial. Ann Am Thorac Soc 2018; 15: 1146-1158. 
Bailey KL, Wyatt TA, Katafiasz DM, et al. Alcohol and cannabis use alter pulmonary innate immunity. Alcohol 2019; 80: 131-138.

106 Ayakannu T, Taylor AH, Marczylo TH, et al. The endocannabinoid system and sex steroid hormone-dependent cancers. Int J Endocrinol 2013; 2013: 259676.

107 Pagotto U, Marsicano G, Cota D, et al. The emerging role of the endocannabinoid system in endocrine regulation and energy balance. Endocr Rev 2006; 27: 73-100.

108 Drehmer MN, Muniz YCN, Marrero AR, et al. Gene expression of ABHD6, a key factor in the endocannabinoid system, can be modulated by female hormones in human immune cells. Biochem Genet 2019; 57: 35-45.

109 Klein TW. Cannabinoid-based drugs as anti-inflammatory therapeutics. Nat Rev Immunol 2005; 5: 400-411.

110 McGarvey LP, Butler CA, Stokesberry S, et al. Increased expression of bronchial epithelial transient receptor potential vanilloid 1 channels in patients with severe asthma. J Allergy Clin Immunol 2014; 133: 704-712 e704.

111 Yocum GT, Chen J, Choi CH, et al. Role of transient receptor potential vanilloid 1 in the modulation of airway smooth muscle tone and calcium handling. Am J Physiol Lung Cell Mol Physiol 2017; 312: L812-L821.

112 Luo J, Schumacher M, Scherer A, et al. A comparison of batch effect removal methods for enhancement of prediction performance using MAQC-II microarray gene expression data. Pharmacogenomics J 2010; 10: $278-291$. 